\title{
ELETRODOS MODIFICADOS POR HIDRÓXIDO DE NÍQUEL: UM ESTUDO DE REVISÃO SOBRE SUAS PROPRIEDADES ESTRUTURAIS E ELETROQUÍMICAS VISANDO SUAS APLICAÇÕES EM ELETROCATÁLISE, ELETROCROMISMO E BATERIAS SECUNDÁRIAS ${ }^{\#}$
}

\author{
Marcio Vidotti \\ Departamento de Química, Universidade Federal do Paraná, CP 19081, 81531-990 Curitiba - PR, Brasil \\ Roberto Torresi e Susana I. Córdoba de Torresi* \\ Instituto de Química, Universidade de São Paulo, CP 26077, 05513-970 São Paulo - SP, Brasil
}

Recebido em 12/5/10; aceito em 13/7/10; publicado na web em 20/10/10

\begin{abstract}
NICKEL HYDROXIDE MODIFIED ELECTRODES: A REVIEW STUDY CONCERNING ITS STRUCTURAL AND ELECTROCHEMICAL PROPERTIES AIMING THE APPLICATION IN ELECTROCATALYSIS, ELECTROCHROMISM AND SECONDARY BATTERIES. The present review paper describes the main features of nickel hydroxide modified electrodes covering its structural and electrochemical behavior and the newest advances promoted by nanostructured architectures. Important aspects such as synthetic procedures and characterization techniques such as X-Ray diffraction, Raman and Infrared spectroscopy, Electronic Microscopy and many others are detailed herein. The most important aspect concerning nickel hydroxide is related to its great versatility covering different fields in electrochemical-based devices such as batteries, electrocatalytic systems and electrochromic electrodes, the fundamental issues of these devices are also commented. Finally, some of the newest advances achieved in each field by the incorporation of nanomaterials will be shown.
\end{abstract}

Keywords: nickel hydroxide; batteries; sensors.

\section{INTRODUÇÃO}

Desde suas primeiras publicações em aplicações eletroquímicas, ${ }^{1}$ o hidróxido de níquel (ou óxido de níquel hidratado, $\mathrm{NiO}_{2} \mathrm{H}$ ) tem sido objeto de um grande número de estudos sobre sua aplicação em baterias secundárias. Em aparelhos portáteis comerciais a bateria mais empregada é a de níquel metal-hidreto, onde o hidróxido de níquel é utilizado como o material ativo no eletrodo positivo. ${ }^{2}$ A melhora de suas propriedades eletroquímicas é de grande interesse e relevância na construção de baterias com maior eficiência de carga. Apesar de certas vantagens, como uma longa vida de ciclagem, o eletrodo de hidróxido de níquel apresenta certos inconvenientes, em particular, um processo de carga limitado. Efetivamente, os potenciais das reações $\mathrm{Ni}(\mathrm{OH})_{2} /$ $\mathrm{NiOOH}$ e $\mathrm{OH} / \mathrm{O}_{2}$ estão muito próximos afetando, desta forma, seu desempenho em aplicações comerciais, além da conversão entre fases, que também limita a eficiência de carga. A fim de solucionar estas deficiências, a utilização de aditivos na matriz inorgânica do hidróxido de níquel é amplamente difundida. ${ }^{3}$

Embora em sua grande maioria os estudos sobre o hidróxido de níquel se concentrem em sua aplicação em baterias, também são encontrados muitos trabalhos que desenvolvem suas propriedades eletrocrômicas, dispositivos como janelas inteligentes, retrovisores de automóveis e óculos podem ser encontrados comercialmente. Neste contexto, filmes finos de hidróxido de níquel em sua forma reduzida são totalmente transparentes adquirindo coloração marrom escuro quando são oxidados a oxi-hidróxido $(\mathrm{NiOOH})$; estes filmes possuem uma boa reversibilidade, além de apresentarem algumas características interessantes como alto contraste, facilidade de síntese, boas eficiências (uma das maiores se comparadas a outros materiais eletrocrômicos inorgânicos) além de um custo bastante baixo dos materiais de partida.

Assim como outros compostos baseados em metais de transição, a presença de sítios de $\mathrm{Ni}^{\mathrm{II}}$, especialmente na sua forma oxidada $\mathrm{Ni}^{\mathrm{III}}$,

\footnotetext{
*e-mail: storresi@iq.usp.br

\#Artigo em homenagem ao Prof. Hans Viertler
}

faz com que o hidróxido de níquel possua uma excelente propriedade eletrocatalítica, orbitais d semipreenchidos são especialmente interessantes na oxidação catalítica de diversas moléculas orgânicas como alcoóis e açúcares e, assim como citado para os dispositivos eletrocrômicos, a utilização do hidróxido de níquel na construção de sensores eletroquímicos é bastante promissora, ${ }^{4}$ especialmente na facilidade de modificação de eletrodos, tanto na forma de filmes finos como na escala micro e nanométrica.

Recentemente, a ciência dos nanomateriais proporcionou um novo e excitante estímulo às "antigas" áreas da tecnologia. Em sua essência, a nanotecnologia consiste na habilidade em se manipular a matéria na escala atômica, com a intenção de se criar estruturas com uma organização molecular diferenciada, utilizando átomos como peças fundamentais, visando um produto final mais resistente, mais barato, mais leve, preciso e adequado. Atualmente, temos algumas aplicações comerciais utilizando materiais nanoestruturados como filtros solares, processos de polimento, capeamento de vidros e, em especial, a fabricação de chips de computadores. Embora as vantagens destes materiais tenham um aspecto promissor, muitas controvérsias surgem quanto à poluição gerada na produção em série desta nova tecnologia, além do fato de algumas destas teorias serem em princípio impossíveis de serem fabricadas com a atual tecnologia. Além disso, existem muitas dúvidas quanto à toxicidade destes novos materiais, em que não é possível prever como o organismo humano ou a natureza irão se comportar frente a estes.

Em termos mais práticos, dentro da pesquisa química, a principal motivação em investimentos envolvendo a escala nanométrica está no estudo de materiais e compostos, que têm suas propriedades químicas potencializadas ou até mesmo alteradas pela simples redução de tamanho. ${ }^{5}$ Materiais nanoestruturados diferenciam-se dos materiais policristalinos convencionais pelo tamanho de seus componentes estruturais unitários, apresentando propriedades que são drasticamente diferentes, essas alterações são resultados dos efeitos quânticos de tamanho, sendo especialmente evidentes em materiais semicondutores, onde temos uma modificação nas suas 
propriedades eletrônicas. Dentro desta nova classe de materiais que sofrem os efeitos quânticos de tamanho é possível citar as mudanças de propriedades magnéticas do óxido de ferro, ${ }^{6}$ as propriedades condutoras de nanotubos de carbono, ${ }^{7}$ a catálise apresentada por nanopartículas de ouro, ${ }^{8}$ a intensificação da banda plasmônica de superfície em metais, ${ }^{9}$ entre outros.

Embora até o momento não tenham sido reportadas mudanças de propriedades fisico-químicas do hidróxido de níquel na escala nanométrica, esta linha de pesquisa está em crescimento exponencial, especialmente devido ao aumento substancial da área superficial do material, onde os processos de superfície, como os de troca iônica e de reações catalíticas, sofreram um grande aumento, levando a eletrodos com desempenho superiores àqueles apresentados por eletrodos massivos, em todos os campos de aplicação deste material.

Desta forma, com esta revisão pretende-se apresentar os aspectos fundamentais do hidróxido de níquel, relacionados à sua estrutura cristalina e suas propriedades eletroquímicas, enfatizando sua aplicação em baterias, dispositivos eletrocrômicos e sensores químicos. Finalmente, serão descritos os mais recentes estudos envolvendo este material na escala nanométrica e como a partir desta nova arquitetura o hidróxido de níquel se tornou um dos principais materiais dentro da ciência e tecnologia.

\section{CARACTERÍSTICAS ESTRUTURAIS}

O hidróxido de níquel possui uma célula unitária do tipo brucita, empacotada em uma distribuição em lamelas ao longo do eixo cristalográfico (001), apresentando distintas variedades estruturais, tanto no estado reduzido como no oxidado, de acordo com a ordenação destas lamelas. Basicamente, pode se apresentar sob dois polimorfos, denominados $\alpha$ e $\beta$, cuja diferença estrutural é o empacotamento ordenado ao longo do eixo cristalográfico c para a estrutura $\beta$ e desordenado para a estrutura $\alpha$, sendo que neste último, moléculas de água e ânions ocupam os espaços entre as camadas. Usualmente, a fase $\beta$ (II)/ $\beta$ (III) representa o material clássico na aplicação em baterias comercias; entretanto, o $\alpha-\mathrm{Ni}(\mathrm{OH})_{2}$, por possuir maior desordem e distanciamento entre as lamelas, possui melhores propriedades eletroquímicas se comparada à fase $\beta,{ }^{10}$ uma vez que desta forma há uma maior exposição dos sítios ativos do hidróxido além da facilidade de difusão iônica. Na Figura 1 é mostrada uma ilustração simplificada das estruturas encontradas no hidróxido de níquel. Este diagrama é conhecido como Diagrama de Bode. ${ }^{11}$

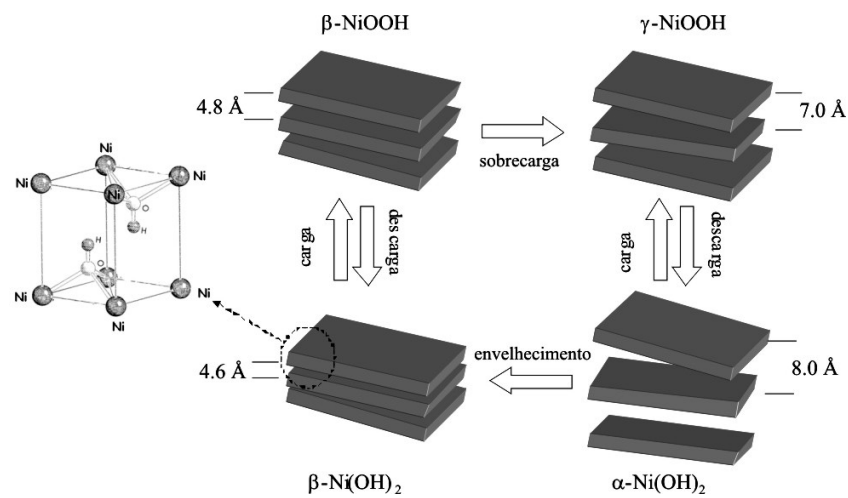

Figura 1. Diagrama de Bode que descreve as diferentes formas estruturais do hidróxido de níquel; no detalhe a estrutura do tipo brucita

Esse diagrama descreve que o $\mathrm{Ni}(\mathrm{OH})_{2}$ e seu composto oxidado $\mathrm{NiOOH}$ podem ambos existir em duas diferentes estruturas, diferenciadas pela organização entre as lamelas. $\mathrm{O} \alpha-\mathrm{Ni}(\mathrm{OH})_{2}$ é altamente desorganizado, possuindo uma distância interlamelar de $8 \AA$, diferente das distâncias encontradas para as estruturas $\beta$ e $\gamma$ com valores de 4,6 e $7 \AA$, respectivamente. A fase $\alpha-\mathrm{Ni}(\mathrm{OH})_{2}$ é convertida em $\beta$ durante a ciclagem contínua, perdendo parte da capacidade de carga. Além disso, a fase $\beta-\mathrm{Ni}(\mathrm{OH})_{2}$ também é convertida na fase $\gamma$, durante uma sobrecarga; porém, essa transformação causa um grande estresse mecânico ao hidróxido, pela variação brusca entre a distância interlamelar, provocando sua irreversibilidade.

A identificação das diferentes fases do hidróxido de níquel pode ser feita por diferentes técnicas de caracterização, porém a difração de Raios X é aquela que apresenta resultados definitivos sobre a fase presente, onde podem ser facilmente obtidos parâmetros como a distância interlamelar e o tamanho do cristal, além de informações referentes ao ordenamento dos planos cristalinos.

Na Figura 2 estão mostradas as principais características cristalográficas encontradas para o hidróxido de níquel, em um trabalho realizado por Faure e colaboradores. ${ }^{12}$ Os autores estimularam quimicamente os processos de carga e descarga do hidróxido de níquel pela utilização de hipoclorito de sódio e peróxido de hidrogênio a partir de uma amostra do $\alpha-\mathrm{Ni}(\mathrm{OH})_{2}$. A primeira linha de difração que aparece a baixos ângulos de difração é referente ao plano (001) e fornece a distância entre as lamelas, como mencionado, maior para a fase alfa. Outra linha de difração interessante é a relacionada ao plano (110) que se levarmos em consideração a simetria hexagonal do hidróxido de níquel fornece o valor $\alpha_{\text {hex }}\left(\alpha_{\text {hex }}=2 \mathrm{~d}_{110}\right)$, aproximadamente $3,1 \AA$, para as duas formas. As lamelas do hidróxido de níquel são paralelas, equidistantes e não orientadas uma em relação à outra produzindo, desta forma, o padrão cristalográfico encontrado entre os valores de $30^{\circ}$ e $45^{\circ}$ em $2 \theta$, também conhecido como desordem turbostrática. ${ }^{12,13}$

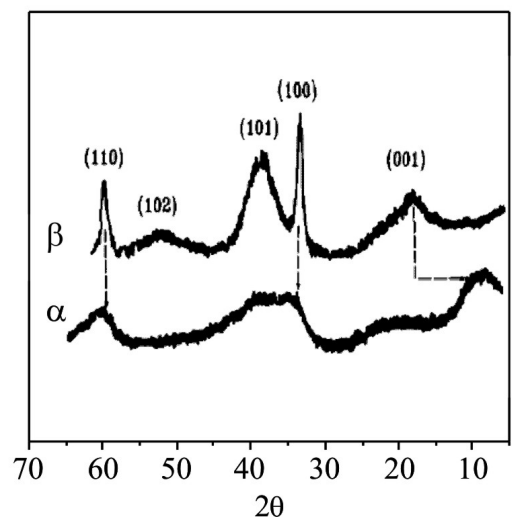

Figura 2. XDR das fases $\alpha$ e $\beta$ do Ni( $\mathrm{OH})_{2}$ obtidos por precipitação, utilizando soluções de $\mathrm{NiSO}_{4}$ e NaOH. Reproduzido da ref. 12, com permissão da Elsevier

Embora a XDR seja a principal técnica de caracterização do hidróxido de níquel, outras técnicas também são encontradas na literatura e podem atuar como informações indiretas na determinação de fases, ou mesmo complementando informações obtidas pelos difratogramas. Uma técnica bastante utilizada é a espectroscopia no infravermelho, ${ }^{14}$ as principais bandas do hidróxido de níquel podem ser encontradas nas regiões de 3600 e $450 \mathrm{~cm}^{-1}$ referentes ao estiramento da hidroxila no retículo do hidróxido de níquel e ao estiramento $\mathrm{Ni}-\mathrm{O}$, respectivamente. Normalmente, a fase $\beta-\mathrm{Ni}(\mathrm{OH})_{2}$ apresenta um pico estreito e intenso em $3600 \mathrm{~cm}^{-1}$, porém devido à presença de moléculas de água além de contraíons remanescentes da síntese (nitrato, sulfato, acetato, etc.) que estão intercalados e/ou adsorvidos no material, torna a espectroscopia no IV uma técnica de caracterização muito limitada, com muitos picos sobrepostos de difícil identificação, inclusive a quantidade de espécies intercaladas pode ser facilmente detectada por experimentos termogravimétricos, ${ }^{15}$ fornecendo informações indiretas quanto à fase estrutural, uma vez que a 
fase $\alpha-\mathrm{Ni}(\mathrm{OH})_{2}$ pode alocar uma maior quantidade destas espécies, devido a um maior espaçamento entre as lamelas.

A espectroscopia Raman vem sendo muito utilizada como técnica de caracterização, uma vez que os problemas encontrados no infravermelho são prontamente minimizados nesta técnica, pois normalmente os espectros Raman apresentam bandas bem definidas e sem sobreposição. A caracterização da fase $\beta-\mathrm{Ni}(\mathrm{OH})_{2}$ pode ser realizada pela análise de um conjunto de bandas em aproximadamente $3680 \mathrm{e}$ $3570 \mathrm{~cm}^{-1}$, atribuídas ao estiramento - $\mathrm{OH}$ na superfície do cristal e entre as lamelas, respectivamente. ${ }^{16}$ Devido ao maior ordenamento da fase $\beta$, essas bandas são estreitas e intensas, podendo ser facilmente diferenciada da fase $\alpha$. Outras bandas podem ser encontradas a baixas frequências, como em 450 e $510 \mathrm{~cm}^{-1}$; essas bandas são atribuídas, respectivamente, ao estiramento $\mathrm{Ni}-\mathrm{O}$ e aos defeitos estruturais. Esses defeitos podem ser descritos como a ausência de átomos de hidrogênio ou hidroxilas na matriz do hidróxido de níquel. ${ }^{17}$

\section{COMPORTAMENTO ELETROQUÍMICO E ELETROGRAVIMÉTRICO}

A reação básica para as reações eletroquímicas do hidróxido de níquel pode ser apresentada como, Equação 1:

$$
\mathrm{Ni}(\mathrm{OH})_{2} \leftrightarrows \mathrm{NiOOH}+\mathrm{H}^{+}+\mathrm{e}^{-}
$$

Porém, as diferentes fases do hidróxido de níquel obviamente apresentam diferentes comportamentos eletroquímicos. Por se tratar de uma reação redox de estado sólido, o aspecto fundamental nestas reações está centrado na troca iônica, onde íons devem ser inseridos/ expelidos da matriz do material para que se obtenha um balanço nas cargas elétricas. Desta forma, a fase $\alpha-\mathrm{Ni}(\mathrm{OH})_{2}$ por apresentar maiores espaços lamelares e mais desordenados possui um comportamento eletroquímico com uma maior capacidade de carga, se comparado com o da fase $\beta-\mathrm{Ni}(\mathrm{OH})_{2}$, uma vez que os processos de troca iônica são mais favorecidos. Na literatura são encontrados diversos trabalhos que empregam a microbalança eletroquímica a cristal de quartzo ${ }^{18}$ (MECQ) como forma de caracterizar este processo de carga e troca iônica, porém esse mecanismo continua sendo foco de muitas discussões sem que seja encontrada uma evidência definitiva para este processo.

Na Figura 3, são apresentados voltamogramas cíclicos obtidos juntamente com a variação de massa do filme depositado, extraídos da ref. ${ }^{19}$. Neste resultado são mostrados os comportamentos das fases $\alpha$ e $\beta$. Como descrito anteriormente é claro que a fase $\alpha-\mathrm{Ni}(\mathrm{OH})_{2}$ possui maior eletroatividade com maior quantidade de carga, além dos picos redox em diferentes posições se comparada com a fase $\beta-\mathrm{Ni}(\mathrm{OH})_{2}$. Analisando a Equação 1, em princípio o processo de oxidação levaria a uma diminuição na massa do material pela expulsão de prótons, como observado para a fase $\beta-\mathrm{Ni}(\mathrm{OH})_{2}$, porém esse comportamento é totalmente diferente para a fase $\alpha-\mathrm{Ni}(\mathrm{OH})_{2}$, onde se verifica um aumento de massa com a oxidação do material, com a inserção de cátions do eletrólito para o material, substituindo desta forma os prótons expelidos no processo de carga. Como mencionado, mesmo sendo um tema bem reportado na literatura, com diversos modelos criados para tentar descrever seu comportamento, ainda não há uma evidência definitiva que responda totalmente as questões deste transporte iônico.

Como citado, seria alcançada maior capacidade de carga com maior durabilidade se os processos de carga do $\mathrm{Ni}(\mathrm{OH})_{2}$ ocorressem somente entre as estruturas $\alpha$ e $\gamma$, pois a formação da fase $\gamma$ a partir da $\beta$ leva ao intumescimento do material, além do estresse mecânico (também conhecido como efeito $\gamma$ ). Para que esses efeitos sejam minimizados, aumentando a vida útil do material é bastante conhecida

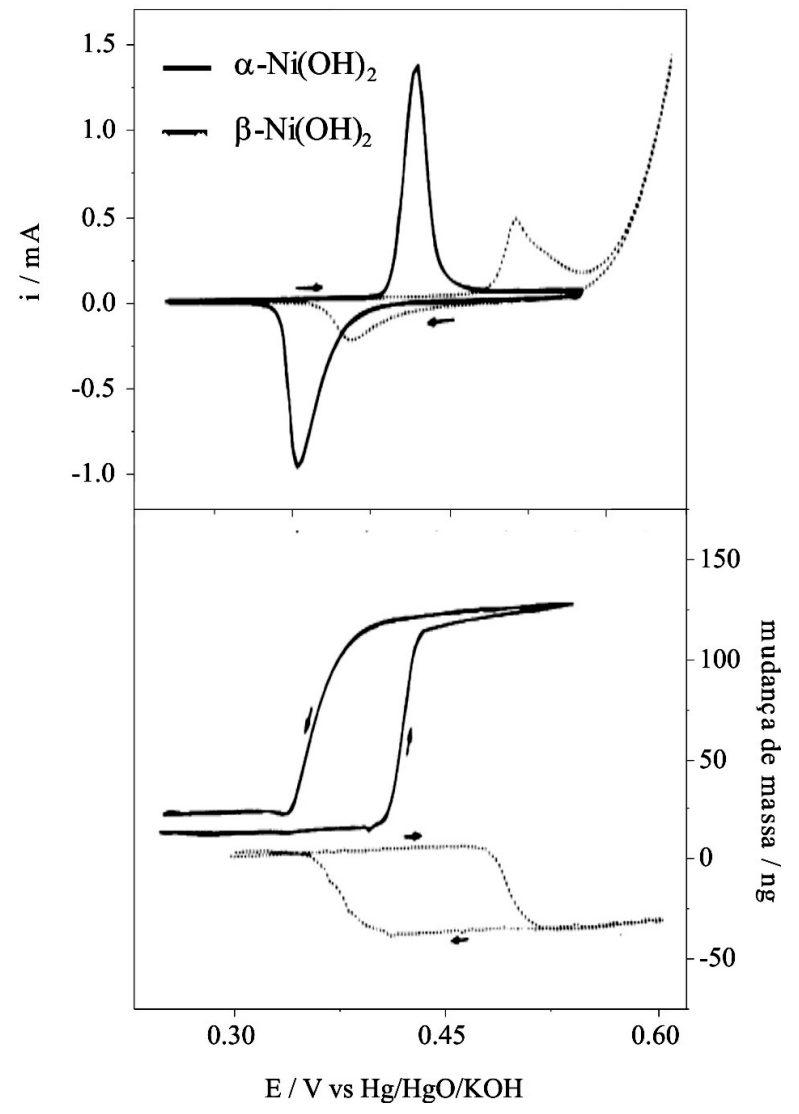

Figura 3. Voltamogramas cíclicos (a) e eletrogravimetria (b) dos filmes de $\mathrm{Ni}(\mathrm{OH})_{2}$ durante a conversão da fase a para a fase b. Eletrólito: $\mathrm{KOH} 1$ mol $L^{-1}$, velocidade de varredura de $10 \mathrm{mVs}^{-1}$. Reproduzido da ref. 19, com permissão da Electrochemical Society

a utilização de aditivos que são incorporados na matriz do hidróxido de níquel. É importante salientar que a conversão da fase $\alpha-\mathrm{Ni}(\mathrm{OH})_{2}$ para a fase $\beta-\mathrm{Ni}(\mathrm{OH})_{2}$ é termodinamicamente favorável, impossível de ser evitada, porém alguns aditivos também atuam como estabilizadores da fase $\alpha-\mathrm{Ni}(\mathrm{OH})_{2}$, fazendo com que esta transformação ocorra com menor velocidade.

\section{UTILIZAÇÃO DE ADITIVOS}

Apesar de ser um material de extrema versatilidade o hidróxido de níquel apresenta alguns inconvenientes, em particular, um processo de carga limitado; além disso, os potenciais das reações de $\mathrm{Ni}(\mathrm{OH})_{2} /$ $\mathrm{NiOOH}$ e $\mathrm{OH}-/ \mathrm{O}_{2}$ são relativamente próximos; o potencial da reação de oxidação do $\mathrm{Ni}(\mathrm{OH})_{2}$ se desloca para potenciais mais positivos com o processo de carga, como resultado da transformação de fases, como mostrado na Figura 3.

O uso de aditivos ao material ativo visa melhorar o desempenho do eletrodo, visto este ser limitado por reações químicas das espécies que participam das reações ou pelo desgaste causado pelos repetitivos ciclos de carga/descarga. Basicamente três características são objetivadas: melhorar a eficiência de carga separando os pares redox; melhorar as propriedades mecânicas e melhorar a condutividade elétrica do material ativo, especialmente no estado reduzido, melhorando desta forma a reversibilidade da reação.

Diferentes aditivos vêm sendo utilizados nos eletrodos de $\mathrm{Ni}(\mathrm{OH})_{2}$, que atuam pela substituição de átomos de níquel no retículo cristalino, levando a um diferente composto com características diferentes dos materiais isolados. Dentre os principais aditivos utilizados, 
Tabela 1. Relação dos principais aditivos utilizados em eletrodos baseados em hidróxido de níquel

\begin{tabular}{|c|c|c|c|c|c|}
\hline Aditivo & Preparação do hidróxido & $\begin{array}{c}\text { Técnicas de caracter- } \\
\text { ização utilizadas }\end{array}$ & Objetivos & Vantagens alcançadas & Ref \\
\hline Alumínio & $\begin{array}{l}\text { Precipitação com uréia a } \\
\text { partir de soluções de propor- } \\
\text { ções definidas dos nitratos de } \\
\text { alumínio e níquel na presença } \\
\text { de surfactantes. A reação foi } \\
\text { conduzida a } 90-95{ }^{\circ} \mathrm{C} \text { por } 3 \mathrm{~h} \text {. }\end{array}$ & $\begin{array}{l}\text { XDR, FTIR, SEM, } \\
\text { curvas de carga-des- } \\
\text { carga galvanostáticas. }\end{array}$ & Baterias & $\begin{array}{l}\text { Proporções maiores que } 16,8 \% \text { em Al mostraram } \\
\text { uma maior estabilidade estrutural na transformação } \\
\text { para a fase } \beta \text {. A adição de } \mathrm{Al}^{3+} \text { melhorou o desem- } \\
\text { penho eletroquímico do } \mathrm{Ni}(\mathrm{OH})_{2} \text {; após } 300 \text { ciclos } \\
\text { de carga-descarga estes eletrodos apresentaram uma } \\
\text { taxa de deterioração de } 10,8 \% \text {. }\end{array}$ & 27 \\
\hline Cobalto & $\begin{array}{l}\text { Mistura dos materiais sólidos, } \\
\text { hidróxidos de níquel e cobalto } \\
\text { com grafite. }\end{array}$ & $\begin{array}{l}\text { XRD, curvas de } \\
\text { carga-descarga } \\
\text { galvanostáticas }\end{array}$ & Baterias & $\begin{array}{l}\text { Maior estabilização da fase } \alpha-\mathrm{Ni}(\mathrm{OH})_{2} \text { durante } \\
\text { longos ciclos e aumento no número de elétrons por } \\
\text { quantidade de material. }\end{array}$ & 28 \\
\hline Manganês & $\begin{array}{l}\text { Eletrodeposição catódica, } \\
\text { empregando correntes de } 120 \\
\mu \mathrm{A} \mathrm{cm} \mathrm{cm}^{-1} \text { por } 5 \text { min, em soluções } \\
\text { contendo diferentes propor- } \\
\text { ções dos nitratos de níquel e } \\
\text { manganês. }\end{array}$ & $\begin{array}{l}\text { Voltamogramas } \\
\text { cíclicos, EDAX, } \\
\text { SEM e UV-Vis } \\
\quad \text { in situ. }\end{array}$ & Eletrocromismo & $\begin{array}{l}\text { Os potenciais redox do par } \mathrm{Ni}(\mathrm{OH})_{2} / \mathrm{NiOOH} \text { foram } \\
\text { deslocados para valores mais catódicos, evitando } \\
\text { em parte a evolução de oxigênio. A quantidade ideal } \\
\text { encontrada foi de } 5 \% \text { em } \mathrm{Mn}^{2+} \text {, apresentando um } \\
\text { aumento na eficiência eletrocrômica. }\end{array}$ & 29 \\
\hline Ferro & $\begin{array}{l}\text { Precipitação química com } \\
\mathrm{NaOH} \text { a partir de solução } \\
\text { aquosa contento } \mathrm{FeCl}_{3}, \mathrm{NiCl}_{2} \text { e } \\
\mathrm{Na}_{2} \mathrm{CO}_{3} \text {, seguida por filtração e } \\
\text { tratamento hidrotérmico. }\end{array}$ & $\begin{array}{l}\text { XRD, FTIR, SEM, } \\
\text { TEM, TGA, BET. }\end{array}$ & $\begin{array}{l}\text { Adsorção de } \\
\text { poluentes }\end{array}$ & $\begin{array}{l}\text { Dependendo do processo hidrotermal, o material } \\
\text { apresenta diferentes fases, sendo mais cristalino } \\
\text { quando temperaturas mais elevadas são empregadas. } \\
\text { O composto formado chegou a remover } 90 \% \text { de } \\
\text { poluentes em apenas } 2 \mathrm{~min} \text {. }\end{array}$ & 30 \\
\hline Cério & $\begin{array}{l}\text { Eletrodeposição galvanostática } \\
\text { a partir da solução aquosa dos } \\
\text { nitratos de níquel e cério (III), } \\
\text { em diferentes proporções. Cor- } \\
\text { rente aplicada de }-0,1 \mathrm{~mA} \mathrm{~cm} \text { cm, }^{-2} \\
\text { durante diferentes tempos. }\end{array}$ & $\begin{array}{l}\text { Voltamogramas } \\
\text { cíclicos, ICP-OES, } \\
\text { Raman. }\end{array}$ & Baterias & $\begin{array}{l}\text { Espectros Raman mostraram a formação de uma } \\
\text { fase estruturada semelhante à } \gamma \text {, porém com pro- } \\
\text { priedades eletroquímicas semelhantes à fase } \alpha \text {. Os } \\
\text { eletrodos apresentaram uma baixa perda de carga } \\
\text { durante a ciclagem contínua. }\end{array}$ & 31 \\
\hline Cádmio & $\begin{array}{l}\text { Eletrodeposição galvanostática } \\
\text { a partir da solução aquosa dos } \\
\text { nitratos de níquel e cádmio. } \\
\text { Corrente aplicada de }-0,1 \mathrm{~mA} \\
\mathrm{~cm}^{-2} \text {, durante diferentes tempos. }\end{array}$ & $\begin{array}{l}\text { Voltamogramas } \\
\text { cíclicos, ICP-OES, } \\
\text { UV-Vis in situ, } \\
\text { AFM. }\end{array}$ & $\begin{array}{l}\text { Estudos } \\
\text { morfológicos } \\
\text { com potenciais } \\
\text { aplicações } \\
\text { eletrocrômicas }\end{array}$ & $\begin{array}{l}\text { Filmes contendo } 2 \% \text { de cádmio mostraram uma alta } \\
\text { reversibilidade eletroquímica com uma superfície } \\
\text { bastante distinta com regiões globulares separadas } \\
\text { por fendas. }\end{array}$ & 32 \\
\hline Zinco & $\begin{array}{l}\text { Eletrodeposição galvanostática } \\
\text { a partir da solução aquosa dos } \\
\text { nitratos de níquel e zinco. }\end{array}$ & $\begin{array}{c}\text { Voltametria cíclica, } \\
\text { MECQ. }\end{array}$ & $\begin{array}{l}\text { Estudos eletro- } \\
\text { gravimétricos } \\
\text { comparando } \\
\text { diferentes aditivos }\end{array}$ & $\begin{array}{l}\text { A adição de zinco confere propriedades eletro- } \\
\text { gravi-métricas únicas ao } \alpha-\mathrm{Ni}(\mathrm{OH})_{2} \text {, que tem um } \\
\text { comportamento similar à fase } \beta, \text { com a diminuição } \\
\text { de massa durante a oxidação e aumento de massa } \\
\text { durante a redução. }\end{array}$ & 33 \\
\hline
\end{tabular}

podemos citar alumínio, ${ }^{20}$ cobalto, ${ }^{21}$ manganês,${ }^{22}$ ferro, ${ }^{23}$ cério ${ }^{24}$, cádmio $^{25}$ e zinco ${ }^{26}$ que, se adicionados em pequenas quantidades ao hidróxido de níquel, levam a melhoras significativas. Na Tabela 1 estão sumarizados alguns dos trabalhos publicados envolvendo a utilização de aditivos nos eletrodos de hidróxido de níquel. ${ }^{27-33}$

Sem dúvida, devido à sua importância, o estudo envolvendo a incorporação de aditivos à matriz do hidróxido de níquel é um assunto extremamente abrangente, com diferentes técnicas de caracterização e aplicações, independentemente da aplicação tecnológica do hidróxido de níquel e indispensável à utilização destes.

\section{NANOESTRUTURAS BASEADAS EM HIDRÓXIDO DE NÍQUEL}

Atualmente a pesquisa em nanomateriais é bastante abrangente e a grande área superficial obtida por estes materiais, além dos efeitos quânticos de tamanho, os torna promissores em diversas áreas da ciência e da tecnologia. Em especial, as nanopartículas de metais e de óxidos são vastamente estudadas devido as suas propriedades elétricas, ópticas, térmicas e catalíticas. ${ }^{6-10}$ Devido à sua grande versatilidade, as pesquisas envolvendo a nanoestruturação do hidróxido de níquel são amplamente encontradas na literatura, ${ }^{34}$ especialmente aquelas baseadas em reações em solução aquosa envolvendo a precipitação do $\mathrm{Ni}(\mathrm{OH})_{2}$ pela utilização direta de bases fortes, como $\mathrm{OH}$ - ou mesmo de forma mais lenta, empregando principalmente uréia, que é degradada a íons amônio e carbonato, levando a um aumento do $\mathrm{pH}$ do meio, precipitando, desta forma, o hidróxido de níquel. ${ }^{35}$ Por envolver altas temperaturas e normalmente passarem por um processo de sinterização, estas nanoestruturas são basicamente na forma $\beta-\mathrm{Ni}(\mathrm{OH})_{2}$ que possui características eletroquímicas menos interessantes se comparada à fase $\alpha-\mathrm{Ni}(\mathrm{OH})_{2}$.

Algumas rotas eletroquímicas de síntese de nanoestruturas têm sendo descritas, todas elas são de certa forma derivadas das sínteses de filmes finos de $\mathrm{Ni}(\mathrm{OH})_{2}$, que empregam a redução de $\mathrm{Ni}^{2+}$ a níquel metálico em soluções aquosas de sulfato/acetato, ${ }^{36}$ seguida pela oxidação ao hidróxido em soluções alcalinas, ou pelo método de Corrigan, ${ }^{37}$ que descreve que a precipitação da forma $\mathrm{Ni}(\mathrm{OH})_{2}$ é devida à redução de nitrato a amônia e $\mathrm{OH}^{-}$. Embora ainda não haja evidências definitivas sobre este mecanismo, ele é bastante utilizado na literatura. Wu et al. ${ }^{38}$ descreveram um método bastante simples na formação de filmes porosos de $\mathrm{Ni}(\mathrm{OH})_{2}$ a partir de uma solução de acetato/sulfato em condições galvanostáticas, seguida por sinterização em diversas temperaturas; o material foi caracterizado por SEM e XDR, além de técnicas eletroquímicas. Em outro trabalho, Nam et al. ${ }^{39}$ sintetizaram nanoestruturas de $\mathrm{Ni}(\mathrm{OH})_{2}$ utilizando diferentes intensidades de correntes catódicas, apresentando estruturas globulares; os eletrodos foram caracterizados por SEM, TGA, XDR e técnicas eletroquímicas. A deposição de $\mathrm{Ni}(\mathrm{OH})_{2}$, sobre nanotubos 
de carbono também é encontrada na literatura, empregando técnicas eletroquímicas de deposição semelhantes às descritas acima. ${ }^{40}$

Uma técnica em particular de preparação de nanomateriais que vem recebendo grande atenção da comunidade científica é aquela assistida por ultrassom, devido a pouca quantidade empregada de material, facilidade experimental e pouco gasto energético.

Algumas teorias foram desenvolvidas para tentar explicar como a radiação sônica de $20 \mathrm{kHz}$ pode provocar a quebra de ligações químicas. ${ }^{41}$ Todas concordam que o principal evento na sonoquímica é a criação, o crescimento e colapso de bolhas que são formadas no líquido, fenômeno conhecido como cavitação acústica. O estágio de colapso da bolha, que ocorre em menos de $1 \times 10^{-9} \mathrm{~s}$, quando o tamanho da mesma atinge seu valor máximo, é que leva à quebra de ligações químicas. Neste processo, temperaturas locais muito altas (5000-25000 K) são obtidas imediatamente após o colapso da bolha. ${ }^{42}$ Uma vez que este colapso ocorre em menos de um nanossegundo, taxas de esfriamento da ordem de $10^{11} \mathrm{~K} \mathrm{~s}^{-1}$ são obtidas. Esta taxa de esfriamento local induz a cristalização e organização dos produtos; por esta razão, em todos os casos onde há volatilização do produto, que se aloja dentro de uma bolha, temos a produção de nanopartículas amorfas.

Porém, enquanto a explicação na formação de compostos amorfos é bem entendida, a razão das dimensões nanométricas ainda não está bem esclarecida. Uma explicação para a formação de nanopartículas através do uso da radiação ultrassônica é que a cinética rápida de formação e colapso de bolhas não permite a formação dos núcleos de crescimento. De outra maneira, se o precursor é um composto não volátil, a reação ocorre em um anel de $200 \mathrm{~nm}$ de diâmetro que envolve a bolha, antes do colapso. ${ }^{28,29}$ Neste caso, a reação se dá na fase líquida. Os produtos encontrados podem ser amorfos ou nanocristalinos, dependendo da temperatura na região do anel onde a reação ocorre. A temperatura deste anel é menor do que dentro da bolha, sendo estimada em aproximadamente $1900^{\circ} \mathrm{C}$, porém maior do que no seio da solução.

Jeevanandam et $a l .{ }^{43}$ descreveram um método ultrassônico na síntese de fibras de $\alpha-\mathrm{Ni}(\mathrm{OH})_{2}$, de cerca de $200 \mathrm{~nm}$ de comprimento e $15 \mathrm{~nm}$ de diâmetro. Para esta síntese, foi utilizada uma frequência de $20 \mathrm{kHz}$ durante $3 \mathrm{~h}$, empregando adição de uréia a uma solução de $\mathrm{Ni}\left(\mathrm{NO}_{3}\right)_{2}$. Em outra síntese ultrassônica, Vidotti et al. ${ }^{44}$ descreveram pela primeira vez a síntese de nanopartículas de $\mathrm{Ni}(\mathrm{OH})_{2}$ aditivadas com cobalto e cádmio, sendo que esta síntese foi efetuada pela mistura dos nitratos dos respectivos metais e pela adição de $\mathrm{NH}_{4} \mathrm{OH}$, com radiação de apenas 5 min e as nanoestruturas foram caracterizadas por HRTEM, XDR, Raman, além de voltametrias cíclicas, apresentando uma alta estabilidade mesmo em períodos elevados de ciclagem. As nanopartículas obtidas são mostradas na Figura 4.

A seguir, descreveremos os principais avanços alcançados por nanoestruturas de hidróxido de níquel, abrangendo eletrocromismo, sensores e baterias.

\section{Eletrocromismo}

Materiais podem ser considerados eletrocrômicos quando mostram distintas mudanças de coloração reversíveis quando submetidos a uma reação de oxidação ou redução, sejam estas mudanças de transparente para colorido, ou mesmo a mudança entre cores. ${ }^{45}$ Em casos em que mais de dois estados redox (e de colorações) são disponíveis, estes materiais são denominados polieletrocrômicos. Na Equação 2 é ilustrada uma reação eletrocrômica catódica, onde o material eletrocrômico é denominado "E". Nesta reação, íons presentes no eletrólito $\left(\mathrm{M}^{+}\right)$são inseridos na matriz do composto para que ocorra a compensação de cargas.

$$
\mathrm{E}+\mathrm{xM}^{+}+\mathrm{xe}^{-} \leftrightarrows \mathrm{M}_{\mathrm{x}} \mathrm{E}
$$

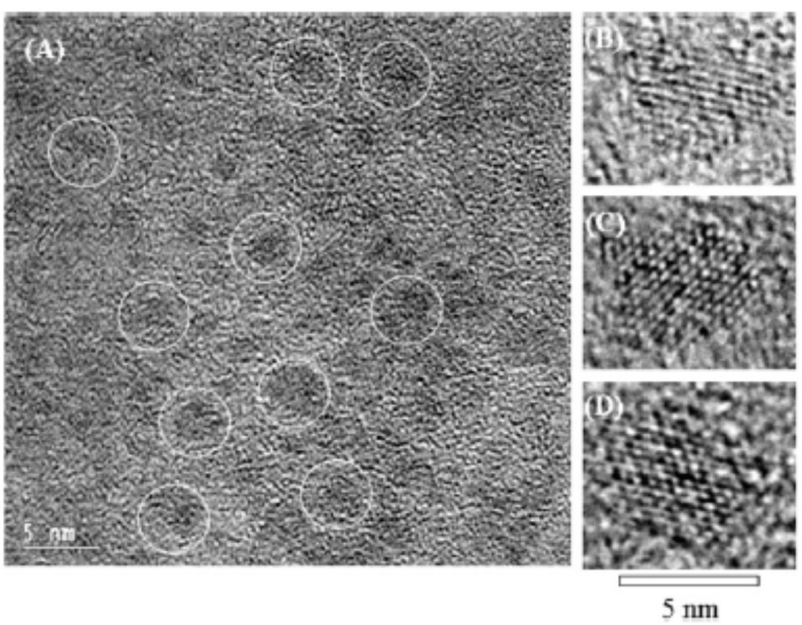

Figura 4. HRTEM obtidas para nanopartículas de $\mathrm{Ni}(\mathrm{OH})_{2}$ em diferentes sínteses: (A) e (D) $\mathrm{Ni}(\mathrm{OH})_{2}$ aditivadas com cobalto e cádmio, $(\mathrm{B}) \mathrm{Ni}(\mathrm{OH})_{2}$ sem aditivos, $(\mathrm{C}) \mathrm{Ni}(\mathrm{OH})_{2}$ aditivado com cobalto. Todas as sínteses foram efetuadas aplicando radiação ultrassônica por 5 min. Reproduzido da ref. 44, com permissão da Elsevier

O desempenho de um sistema eletrocrômico pode ser medido por meio de diversos parâmetros, porém, três deles têm maior relevância: eficiência eletrocrômica, contraste (variação de transmitância, $\Delta \% \mathrm{~T}$ ) e tempo de resposta.

A eficiência eletrocrômica $(\eta)$, a um determinado comprimento de onda $(\lambda)$, é definida como a variação de absorbância $(\Delta \mathrm{A})$ quando certa carga elétrica $(\mathrm{Q})$ é fornecida, por unidade de área, como mostrada na Equação 3. A unidade da eficiência eletrocrômica é $\mathrm{cm}^{2} \mathrm{C}^{-1}$.

$$
\eta(\lambda)=\frac{\Delta \mathrm{A}}{\mathrm{Q}}
$$

Embora $\eta$ seja uma medida do desempenho de um material eletrocrômico, deve ser analisada juntamente com a variação de contraste apresentada $(\Delta \% \mathrm{~T})$, pois é possível encontrar materiais com valor alto de eficiência eletrocrômica, porém com baixos valores de contraste, o que não é interessante do ponto de vista comercial.

O tempo de resposta eletrocrômico $(\tau)$ é o tempo necessário para que o material mude sua cor. Para a maioria dos materiais, este tempo está na ordem de segundos, porém em dispositivos comerciais de grande área, são encontrados tempos de resposta da ordem de minutos. Infelizmente, não há um critério específico para se determinar $\tau$, podendo ser definido pela variação total da transmitância (ou absorbância) ou por uma fração desta.

O hidróxido de níquel é um material eletrocrômico anódico, onde a forma oxidada $\mathrm{NiOOH}$ possui uma coloração marrom escuro, em contraste com a transparência apresentada pela forma reduzida $\mathrm{Ni}(\mathrm{OH})_{2}$, onde a compensação de cargas promovida pela incorporação de cátions é a principal característica a ser melhorada pelas nanoestruturas. Um material altamente poroso, que permita a movimentação iônica com mais facilidade, irá influenciar em todos os parâmetros eletrocrômicos, onde maior quantidade de sítios ativos estará exposta, aumentando o contraste e a eficiência eletrocrômica, além de diminuir os tempos de resposta, fundamental para dispositivos eletrocrômicos de alto desempenho, onde tempos na ordem de milisegundos são requeridos. ${ }^{46}$

A síntese de nanoestruturas de $\mathrm{Ni}(\mathrm{OH})_{2}$ é bastante variada, porém para eletrodos eletrocrômicos, devido à utilização de eletrodos transparentes (FTO, ITO, etc) é muito importante que o depósito de material seja feito de forma homogênea; desta forma, é necessário que o processo de imobilização das nanoestruturas sobre o eletrodo 
seja efetuado de forma controlada. Dentre os diversos métodos de imobilização, um em especial vem sendo amplamente utilizado em diversas áreas da ciência, a deposição por camadas eletrostáticas (layer by layer - LbL). O processo de crescimento das camadas é efetuado por uma forte atração eletrostática, que ocorre entre uma superfície carregada (o substrato) e uma molécula eletricamente carregada com carga oposta. Em princípio, a adsorção de moléculas/ nanoestruturas contendo mais que uma carga igual leva à reversão da carga na superfície, sendo que este fenômeno possui duas importantes consequências: repulsão de moléculas igualmente carregadas e, desta maneira, a autorregulação da adsorção e restrição de uma única camada e, a habilidade de uma molécula carregada com carga oposta de ser adsorvida, em uma segunda etapa, na superfície da primeira molécula. A repetição cíclica destas etapas de adsorção leva à formação de estruturas em multicamadas. As maiores vantagens da adsorção por camadas a partir de uma solução são que muitos materiais diferentes podem ser incorporados em filmes individuais multicamada e que as formas do filme são completamente determinadas pela sequência de deposição. ${ }^{47}$

Uma alternativa encontrada na técnica de LbL é a deposição eletroforética, alcançada pela movimentação de partículas carregadas dispersas em um líquido através de um campo elétrico aplicado, resultando em um acúmulo destas, formando um depósito homogêneo sobre a superfície de um dos eletrodos. Após a deposição, em alguns processos é necessário um tratamento térmico sobre o eletrodo a fim de eliminar o excesso de rugosidade. Em geral, a técnica pode ser aplicada a qualquer sólido na forma de pó fino $(<30 \mu \mathrm{m})$ ou a partir de uma suspensão coloidal. ${ }^{48} \mathrm{Na}$ área de nanomateriais, a técnica de EDP já foi empregada no crescimento e deposição de nanotubos e nanorods de materiais cerâmicos, além da própria deposição de nanopartículas eletricamente carregadas superficialmente. ${ }^{49}$

Em recente publicação, ${ }^{50}$ as técnicas de deposição por eletroforese e camadas eletrostáticas foram comparadas quando empregadas na

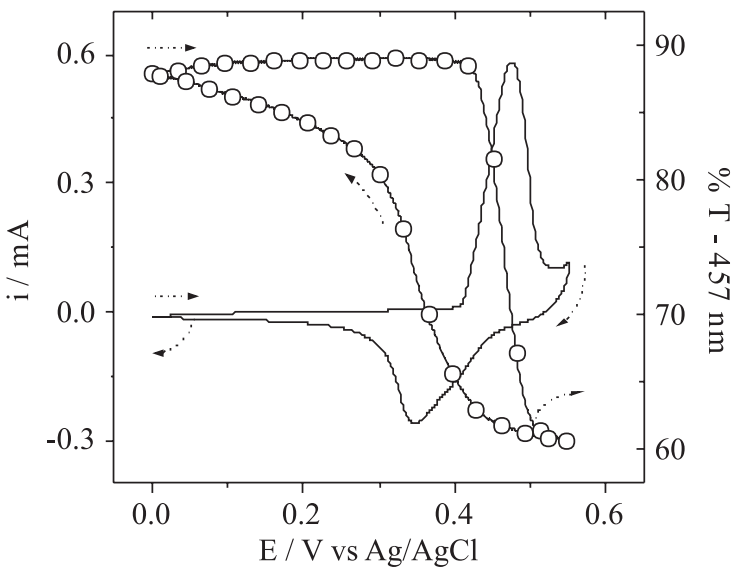

Figura 5. Voltamogramas in situ utilizando radiação incidente monocromática (457 $\mathrm{nm}$ ) e um eletrodo modificado por um filme de $\mathrm{Ni}(\mathrm{OH})_{2}$ eletrossintetizado, aplicando uma corrente galvanostática de $-0,1 \mathrm{~mA} \mathrm{~cm}^{-2}$ durante $30 \mathrm{~s}$ em uma solução $10 \mathrm{mM}$ de $\mathrm{Ni}\left(\mathrm{NO}_{3}\right)_{2}$, substrato: ITO. Eletrólito: $\mathrm{KOH} \mathrm{0,1} \mathrm{mol} \mathrm{L}^{-1}$, velocidade de varredura de $10 \mathrm{mVs}^{-1}$

imobilização de nanopartículas de $\mathrm{Ni}(\mathrm{OH})$, aditivadas, onde a EPD mostrou características mais interessantes, como alta eficiência eletrocrômica, baixos tempos de resposta e uma grande durabilidade do eletrodo. Se comparada com a técnica de LbL, esta melhora foi atribuída ao aumento da conectividade elétrica entre as nanopartículas, além de melhora no transporte iônico, devido à ausência de policátions isolantes entre camadas de material eletroativo.

Um experimento eletrocrômico típico envolvendo eletrodos modificados por $\mathrm{Ni}(\mathrm{OH})_{2}$ está mostrado na Figura 5, onde um filme fino foi eletroquimicamente depositado sobre ITO. Neste caso, juntamente com o voltamograma é obtida a variação de transmitância do eletrodo, que de transparente na sua forma reduzida $\left(\mathrm{Ni}(\mathrm{OH})_{2}\right)$ é convertida

Tabela 2. Relação dos principais trabalhos envolvendo a utilização do hidróxido de níquel em eletrocromismo

\begin{tabular}{|c|c|c|c|c|c|}
\hline Modificação de eletrodo & Técnicas de caracterização & $\begin{array}{l}\text { Eficiência eletro- } \\
\text { crômica }\end{array}$ & $\begin{array}{l}\text { Tempo de res- } \\
\text { posta }\end{array}$ & Durabilidade & Ref. \\
\hline $\begin{array}{l}\text { Nanopartículas de } \mathrm{Ni}(\mathrm{OH})_{2} \text { aditivadas com cobalto } \\
\text { e cádmio sintetizadas via radiação ultrassônica e } \\
\text { adsorvidas em ITO via deposição eletroforética } \\
\left(\mathrm{E}=1,0 \mathrm{~V} \mathrm{~cm}^{-1}\right)\end{array}$ & $\begin{array}{l}\text { AFM, VC, cronoamperome- } \\
\text { tria, espectroeletroquímica na } \\
\text { região VIS }\end{array}$ & $\begin{array}{c}90 \mathrm{C}^{-1} \mathrm{~cm}^{2} \\
(\lambda=457 \mathrm{~nm})\end{array}$ & $\begin{array}{c}0,3 \mathrm{~s} \\
(\lambda=457 \mathrm{~nm}) \\
\text { coloração }\end{array}$ & $\begin{array}{l}\text { Após } 20 \text { h de cicla- } \\
\text { gem ocorreu uma } \\
\text { perda de } 1 \% \text { na } \Delta \mathrm{A}\end{array}$ & 50 \\
\hline $\begin{array}{l}\text { Filmes finos de } \mathrm{Ni}(\mathrm{OH})_{2} \text { depositados sobre ITO } \\
\text { através de eletrólise anódica empregando o complexo } \\
\mathrm{Ni}\left(\mathrm{NH}_{3}\right)_{\mathrm{x}}{ }^{2+}\end{array}$ & $\begin{array}{l}\text { Voltametria cíclica, AAS, es- } \\
\text { pectroeletroquímica na região } \\
\text { VIS, XDR }\end{array}$ & $\begin{array}{c}52 \mathrm{C}^{-1} \mathrm{~cm}^{2} \\
(\lambda=550 \mathrm{~nm})\end{array}$ & $\begin{array}{l}27 \mathrm{~s} \\
(\lambda=550 \mathrm{~nm}) \\
\text { coloração }\end{array}$ & $\begin{array}{l}\text { Após } 20 \text { h de cicla- } \\
\text { gem ocorreu uma } \\
\text { perda de } 25 \% \text { na } \Delta \mathrm{A}\end{array}$ & 51 \\
\hline $\begin{array}{l}\text { Nanopartículas de } \mathrm{Ni}(\mathrm{OH})_{2} \text { sintetizadas via precipi- } \\
\text { tação química com ácido acético. A solução coloidal } \\
\text { foi espalhada em ITO e sinterizada a } 270^{\circ} \mathrm{C}\end{array}$ & $\begin{array}{l}\text { VC, cronoamperometria, IV, } \\
\text { TEM, TGA, espectroeletro- } \\
\text { química na região VIS }\end{array}$ & $\begin{array}{c}40 \mathrm{C}^{-1} \mathrm{~cm}^{2} \\
(\lambda=480 \mathrm{~nm})\end{array}$ & $\begin{array}{l}\text { Cerca de } 7 \mathrm{~s} \\
(\lambda=480 \mathrm{~nm}) \\
\text { coloração }\end{array}$ & Não informado & 52 \\
\hline $\begin{array}{l}\text { Nanopartículas de } \mathrm{Ni}(\mathrm{OH})_{2} \text { aditivadas com lantânio } \\
\text { foram sintetizadas via precipitação química com } \\
\text { ácido acético. As nanoestruturas foram adsorvidas } \\
\text { em FTO através de dip-coating e sinterizada a } 300^{\circ} \mathrm{C}\end{array}$ & $\begin{array}{l}\text { XDR, IV, VC, cronoampero- } \\
\text { metria, espectroeletroquímica } \\
\text { na região VIS, TGA, profilo- } \\
\text { metria }\end{array}$ & $\begin{array}{c}28 \mathrm{C}^{-1} \mathrm{~cm}^{2} \\
(\lambda=480 \mathrm{~nm})\end{array}$ & $\begin{array}{l}\text { Cerca de } 7 \mathrm{~s} \\
(\lambda=480 \mathrm{~nm}) \\
\text { coloração }\end{array}$ & Não informado & 53 \\
\hline $\begin{array}{l}\text { Nanopartículas de } \mathrm{Ni}(\mathrm{OH})_{2} \text { sintetizadas via ultrassom } \\
\text { e imobilizadas sobre ITO através de deposição por } \\
\text { camadas eletrostáticas empregando PAH como } \\
\text { policátion }\end{array}$ & $\begin{array}{l}\text { VC, espectroeletroquímica na } \\
\text { região VIS, TEM, ICP-OES }\end{array}$ & $\begin{array}{c}80 \mathrm{C}^{-1} \mathrm{~cm}^{2} \\
(\lambda=457 \mathrm{~nm})\end{array}$ & $\begin{array}{l}0,3 \mathrm{~s} \\
(\lambda=457 \mathrm{~nm}) \\
\text { coloração }\end{array}$ & $\begin{array}{l}\text { Após } 1 \mathrm{~h} \text { de ciclagem } \\
\text { ocorreu uma perda de } \\
\qquad 20 \% \text { na } \Delta \mathrm{A}\end{array}$ & 54 \\
\hline $\begin{array}{l}\text { Filmes finos de } \mathrm{Ni}(\mathrm{OH})_{2} \text { foram depositados sobre } \\
\text { FTO potenciostatica-mente a partir de uma solução } \\
\text { contendo } \mathrm{NiCl}_{2} \text { e EDTA }\end{array}$ & $\begin{array}{l}\text { XDR, IV, VC, cronoampero- } \\
\text { metria, espectroeletroquímica } \\
\text { na região VIS, SEM, EQCM }\end{array}$ & $\begin{array}{l}107 \mathrm{C}^{-1} \mathrm{~cm}^{2} \\
(\lambda=633 \mathrm{~nm})\end{array}$ & Não informado & $\begin{array}{l}\text { Ciclagem por mais de } \\
10^{4} \text { ciclos contínuos }\end{array}$ & 55 \\
\hline $\begin{array}{l}\text { Solução coloidal de } \mathrm{Ni}(\mathrm{OH})_{2} \text { sintetizada via precipi- } \\
\text { tação química de } \mathrm{NiSO}_{4} \text { e LiOH, seguida da adição } \\
\text { de estabilizadores químicos como glicerol e álcool } \\
\text { polivinílico. O material foi adsorvido em FTO através } \\
\text { de dip-coating e posteriormente sinterizada a } 300^{\circ} \mathrm{C}\end{array}$ & $\begin{array}{l}\text { VC, espectroeletroquímica } \\
\text { na região VIS, IV }\end{array}$ & $\begin{array}{l}23,5 \mathrm{C}^{-1} \mathrm{~cm}^{2} \\
(\lambda=400 \mathrm{~nm})\end{array}$ & $\begin{array}{l}25 \mathrm{~s} \\
(\lambda=400 \mathrm{~nm}) \\
\text { coloração }\end{array}$ & Não informado & 56 \\
\hline
\end{tabular}


à coloração marrom devido à oxidação a $\mathrm{NiOOH}$, sendo observada a reversibilidade do sistema; ao ser reduzido o eletrodo volta a ser transparente e, consequentemente, seu valor de transmitância retorna ao valor inicial.

Na Tabela 2 estão mostrados alguns trabalhos envolvendo o eletrocromismo de $\mathrm{Ni}(\mathrm{OH})_{2}$, descrevendo as rotas sintéticas e principais parâmetros eletrocrômicos obtidos. É importante salientar que os parâmetros eletrocrômicos são diretamente influenciados pela morfologia dos eletrodos modificados, uma vez que dependendo desta, a troca iônica é feita de maneira mais rápida, resultando em menores tempos de resposta, da mesma forma a condutividade elétrica do filme e sua espessura influenciará diretamente na eficiência eletrocrômica. ${ }^{50-515253545556}$

\section{Sensores/eletrocatálise}

O desenvolvimento de sensores e biossensores sempre foi de grande destaque no meio científico, pois estes dispositivos permitem a identificação e quantificação de diversas espécies, desde metais pesados a complexas estruturas orgânicas. A grande vantagem destes sistemas está na possibilidade de se construir dispositivos em miniatura facilitando medidas in loco, além do fato de serem obtidas respostas praticamente instantâneas, dispensando laboriosos trabalhos de separação e análise. Dentre os diversos tipos de sensores, os eletroquímicos são os mais empregados devido à sua facilidade $\mathrm{e}$ baixo custo de construção e de resultados de fácil análise, sendo que a corrente elétrica gerada pode ser prontamente relacionada com a concentração do analito.

A principal diferença entre sensores e biossensores é a presença de espécies biológicas imobilizadas neste último. Essas espécies podem ser DNA/RNA, micro-organismos, antígenos/anticorpos, células ou, mais comumente, enzimas. Estas biomoléculas atuam na conversão do analito a outras espécies que podem ser detectadas pelo eletrodo, onde pode estar presente um segundo material catalítico. Em enzimas redox, esta conversão é realizada mediante o consumo/ fornecimento de elétrons, diretamente pelo eletrodo ou por cofatores como o NADH, que são posteriormente eletroquimicamente regenerados pelo eletrodo ${ }^{57}$ Sem dúvida, a principal vantagem apresentada pelos biossensores está na especificidade de detecção, porém vários problemas como durabilidade, reprodutibilidade, alto custo de enzimas fazem com que os biossensores não sejam encontrados em grande escala no mercado, salvo pelos biossensores de glicose que são amplamente difundidos na sociedade atual.

Nos sensores eletroquímicos, a modificação de eletrodos normalmente é realizada de forma mais simples e menos dispendiosa. $\mathrm{O}$ analito pode ser prontamente identificado utilizando-se eletrodos convencionais, como platina, ouro, carbono vítreo, etc, porém dependendo da reação redox, são requeridos altos valores de potenciais. Desta forma, é bastante empregada a modificação de eletrodos por materiais eletrocatalíticos, como polímeros condutores, ${ }^{58}$ complexos de metais de transição $0^{59} \mathrm{e}$ óxidos metálicos. ${ }^{60} \mathrm{Na}$ Figura 6 são mostradas esquematicamente as configurações dos sensores e biossensores.

Não se encontram muitos trabalhos que empreguem o hidróxido de níquel em biossensores, uma vez que o $\mathrm{pH}$ necessário para que este apresente eletroatividade é moderadamente elevado $(\mathrm{pH}>10)$, limitando o uso de biomoléculas. Porém, sua utilização em sensores é amplamente difundida, apresentando uma alta atividade eletrocatalítica; especialmente na sua forma oxidada, $\mathrm{NiOOH}$, a presença de orbitais d incompletos faz com que diversas moléculas orgânicas sejam prontamente oxidadas quando em contato com o $\mathrm{NiOOH}$. Em especial, a utilização de materiais catalíticos não nobres diminui consideravelmente o preço para uma possível produção em grande escala. Na Figura 7 é apresentado o comportamento eletrocatalítico (a)

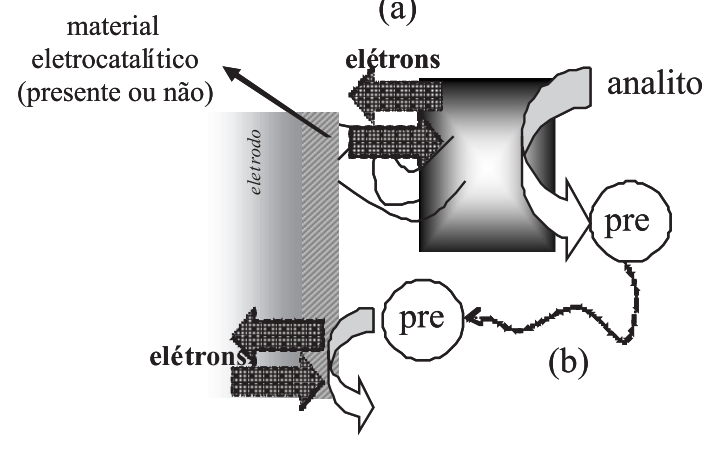

$\underline{\text { biossensores }}$

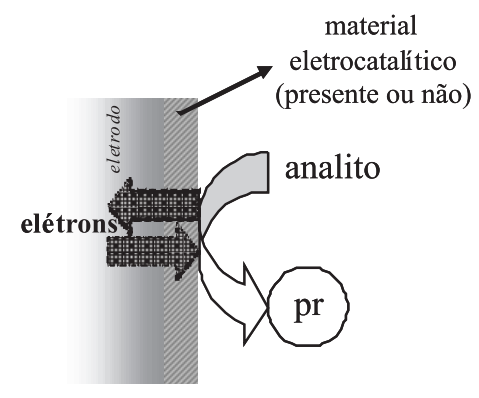

$\underline{\text { sensores }}$

Figura 6. Esquematização de sensores e biossensores eletroquímicos. Nos biossensores a biomolécula está imobilizada sobre o eletrodo, onde é possível a prévia imobilização de um material eletrocatalítico: (a) os elétrons são coletados/fornecidos diretamente da/pela biomolécula após reação com o analito; (b) os produtos da reação enzimática (pre) difundem até a superfície do eletrodo para sofrerem a reação redox. Nos sensores, o analito é diretamente convertido em produtos na superfície do eletrodo/material eletrocatalítico, gerando ou recebendo os elétrons

do NiOOH na oxidação de glicose, onde um aumento da concentração desta provoca um aumento na corrente amperométrica; é importante observar que embora a glicose esteja presente durante toda a ciclagem, ela somente é oxidada após a conversão da forma $\mathrm{Ni}(\mathrm{OH})_{2}$ a $\mathrm{NiOOH}$.

Basicamente todos os sensores que empregam eletrodos modificados por hidróxido de níquel atuam da mesma forma, sendo que os compostos orgânicos são cataliticamente oxidados pela forma $\mathrm{NiOOH}$. Além da glicose e outros açúcares, ${ }^{61}$ podem ser encontrados na literatura sensores eletroquímicos para a detecção de uréia, ${ }^{62}$ aminoácidos, ${ }^{63}$ sulfito, ${ }^{64}$ alcoóis ${ }^{65}$ e até mesmo anti-inflamatórios. ${ }^{66}$ Dentre todos os analitos possíveis de serem detectados pelo $\mathrm{Ni}(\mathrm{OH})_{2}$, sem dúvida a glicose é a mais reportada. Os eletrodos modificados podem ser encontrados em diferentes formas e arquiteturas; na Tabela 3 estão descritos alguns trabalhos com esta finalidade, enfatizando a modificação de eletrodos e seu desempenho analítico. Para efeitos de comparação, também são mostrados alguns trabalhos envolvendo outros materiais catalíticos na detecção de glicose e biossensores, empregando a enzima Glicose oxidase. ${ }^{67-75}$

Embora seja um material com alta propriedade eletrocatalítica, um dos problemas encontrados na utilização do $\mathrm{Ni}(\mathrm{OH})_{2}$ em dispositivos analíticos é sua falta de especificidade; desta forma, é necessário um pré-tratamento da amostra, especialmente para que seus componentes sejam separados. A facilidade de modificação de qualquer tipo de eletrodo com o $\mathrm{Ni}(\mathrm{OH})_{2}$ faz com que possa ser acoplado a diferentes técnicas de análise, visando a separação de componentes. Foi recentemente publicado ${ }^{70} \mathrm{o}$ acoplamento de eletrodos modificados por $\mathrm{Ni}(\mathrm{OH})_{2}$ a um HPLC para a detecção de amostras multicompo- 


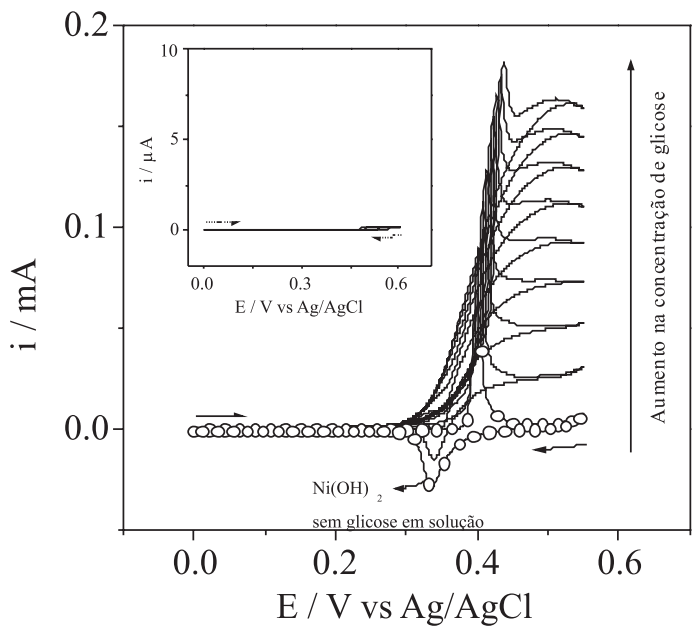

Figura 7. Eletrocatálise na detecção de glicose efetuada por filmes finos de $\mathrm{Ni}(\mathrm{OH})_{2}$ crescidos eletroquimicamente, aplicando-se uma corrente galvanostática de $-0,1 \mathrm{~mA} \mathrm{~cm}^{-2}$ durante $30 \mathrm{~s}$ em uma solução $10 \mathrm{mM}$ de $\mathrm{Ni}\left(\mathrm{NO}_{3}\right)_{2}$, substrato: carbono vítreo. Eletrólito: $\mathrm{KOH} 0,1 \mathrm{~mol} \mathrm{~L}^{-1}$, velocidade de varredura de $10 \mathrm{mV}^{-1}$. Cada voltamograma foi obtido com uma diferente concentração de glicose. No detalhe está mostrado um voltamograma cíclico do eletrodo de carbono vítreo não modificado em $\mathrm{KOH} \mathrm{O,1} \mathrm{mol} \mathrm{L}^{-1}$ na presença de $1 \mathrm{~mol} \mathrm{~L}^{-1}$ de glicose

nentes. Na Figura 8 é mostrada a detecção amperométrica de uma amostra contendo glicose, frutose, sacarose e lactose, por eletrodos modificados por filmes finos de $\mathrm{Ni}(\mathrm{OH})_{2}$.

A eletrocatálise apresentada pelo hidróxido de níquel também abre a possibilidade de estudos envolvendo formas alternativas de geração de energia. O desenvolvimento de células a combustível baseadas em oxidação de alcoóis tem recebido grande atenção da comunidade científica nos últimos anos, pois apresenta uma boa alternativa para a produção de eletricidade. ${ }^{76}$ Aspectos como mobilidade, distribuição, operação e armazenamento de células são questões que ainda precisam ser melhorados, por exemplo, catalisadores mais baratos são muito interessantes ao invés de usar metais nobres e ligas tais como Pt, Pt-Rh, Pt-Ru etc, que são frequentemente utilizadas. ${ }^{77}$ Além disso, a oxidação de alcoóis em condições alcalinas apresenta

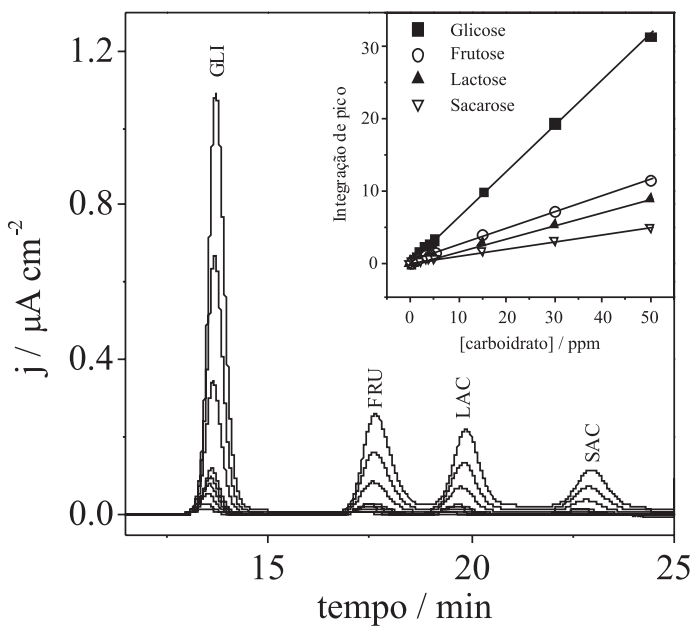

Figura 8. Detecção amperométrica de carboidratos efetuada por eletrodo modificado por $\mathrm{Ni}(\mathrm{OH})_{2}$. As soluções foram eluídas através de coluna cro-

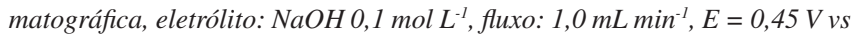
$\mathrm{Ag} / \mathrm{AgCl}$. Reproduzido da ref. 70, com autorização da Elsevier

muitas vantagens, tais como um aumento da eficiência. ${ }^{78}$ Portanto, o uso de eletrodos baseados em hidróxido de níquel preenche satisfatoriamente muitos desses aspectos, além é claro da grande área reativa fornecida na utilização de nanoestruturas, aumentando ainda mais a eficiência de conversão de energia. ${ }^{79}$

\section{Baterias secundárias}

São dispositivos capazes de armazenar energia química e convertê-la em energia elétrica (descarga), podendo ser recarregados pela passagem de corrente pelo sistema (carga). As baterias comercializadas atualmente são as de íon lítio, empregadas extensivamente em equipamentos portáteis, tais como telefones celulares, laptops e câmeras digitais. Estes dispositivos são constituídos de cátodo de óxido de cobalto, ânodo de carbono e solução eletrolítica de sal de lítio $\left(\mathrm{LiPF}_{6}\right)$ dissolvido em solventes orgânicos (como carbonato de propileno) ${ }^{80} \mathrm{~A}$ substituição dos materiais utilizados nas baterias atuais pode melhorar o seu desempenho e segurança.

Tabela 3. Relação dos principais trabalhos envolvendo a utilização do hidróxido de níquel em sensores eletroquímicos

\begin{tabular}{|c|c|c|c|c|}
\hline Modificação de eletrodo & Técnica empregada na detecção & $\begin{array}{l}\text { Sensibilidade } \\
\left(\mu \mathrm{A} \mathrm{mM} \mathrm{cm}^{-2}\right)\end{array}$ & $\begin{array}{l}\text { Limite de detecção } \\
\qquad\left(\mathrm{mol} \mathrm{L}^{-1}\right)\end{array}$ & Ref. \\
\hline $\begin{array}{l}\text { Nanopartículas de } \mathrm{Ni}(\mathrm{OH})_{2} \text { misturadas com pó } \\
\text { de grafite e líquido iônico }\end{array}$ & $\begin{array}{l}\text { Cronoamperometria a } 0,55 \mathrm{~V} \text { vs } \mathrm{Ag} / \mathrm{AgCl} \text {. Eletrólito: } \\
\qquad \mathrm{NaOH} 0,5 \mathrm{~mol} \mathrm{~L}^{-1}\end{array}$ & 200 & $60 \times 10^{-7}$ & 67 \\
\hline Nanopartículas de níquel dispersas em grafite & FIA a $0,4 \mathrm{~V}$ vs Ag/AgCl. Eletrólito: $\mathrm{NaOH} 0,1 \mathrm{~mol} \mathrm{~L}^{-1}$ & 40 & $0,2 \times 10^{-7}$ & 68 \\
\hline $\begin{array}{l}\text { Filmes de } \mathrm{Ni}(\mathrm{OH})_{2} \text { eletrodepositados sobre } \\
\text { eletrodos de ouro }\end{array}$ & FIA a $0,6 \mathrm{~V}$ vs $\mathrm{Ag} / \mathrm{AgCl}$. Eletrólito: $\mathrm{NaOH} 0,2 \mathrm{~mol} \mathrm{~L}^{-1}$ & 222 & $1,8 \times 10^{-7}$ & 69 \\
\hline $\begin{array}{l}\text { Filmes finos de } \mathrm{Ni}(\mathrm{OH})_{2} \text { eletrodepositados sobre } \\
\text { carbono vítreo }\end{array}$ & $\begin{array}{l}\text { Voltametria cíclica a } 10 \mathrm{mVs}^{-1} \text {. Eletrólito } \mathrm{KOH} \\
\qquad 0,1 \mathrm{~mol} \mathrm{~L}^{-1}\end{array}$ & 150 & $34 \times 10^{-7}$ & 70 \\
\hline $\begin{array}{l}\text { Nanoestruturas de } \mathrm{Ni}(\mathrm{OH})_{2} \text { imobilizadas sobre } \\
\mathrm{TiO}_{2}\end{array}$ & $\begin{array}{l}\text { Cronoamperometria a } 0,6 \mathrm{~V} \text { vs ECS. Eletrólito } \mathrm{KOH} \\
\qquad 0,5 \mathrm{~mol} \mathrm{~L}^{-1}\end{array}$ & 7 & Não informado & 71 \\
\hline Filmes porosos de ouro & $\begin{array}{l}\text { Cronoamperometria a } 0,35 \mathrm{~V} \text { vs ECS. Eletrólito PBS } \\
\qquad 0,1 \mathrm{~mol} \mathrm{~L}^{-1}\end{array}$ & 12 & $50 \times 10^{-7}$ & 72 \\
\hline Nanotubos de carbono de multiparedes & $\begin{array}{l}\text { Cronoamperometria a } 0,2 \mathrm{~V} \text { vs Ag/AgCl. Eletrólito } \\
\qquad \mathrm{NaOH} 0,1 \mathrm{~mol} \mathrm{~L}^{-1}\end{array}$ & 4 & $10 \times 10^{-7}$ & 73 \\
\hline $\begin{array}{l}\text { GOx imobilizada em filmes de } \mathrm{TiO}_{2} \text { sobre } \\
\text { carbono vítreo }\end{array}$ & FIA a $0,3 \mathrm{~V}$ vs ECS. Eletrólito PBS $0,01 \mathrm{~mol} \mathrm{~L}^{-1}$ & 8,3 & Não informado & 74 \\
\hline $\begin{array}{l}\text { GOx imobilizada sobre filmes de poli(pirrol) } \\
\text { eletrodepositado sobre } \mathrm{TiO}_{2}\end{array}$ & $\begin{array}{l}\text { Cronoamperometria a }-0,15 \mathrm{~V} \text { vs } \mathrm{Ag} / \mathrm{AgCl} \text {. Eletrólito: } \\
\qquad \mathrm{LiClO}_{4} 0,1 \mathrm{~mol} \mathrm{~L}^{-1}\end{array}$ & 4 & Não informado & 75 \\
\hline
\end{tabular}


Os óxidos de metais de transição apresentam boa capacidade, alta energia específica e boa ciclabilidade. Os óxidos de cobalto atualmente utilizados, porém, apresentam problemas ambientais e relacionados à toxicidade. Muitos esforços vêm sendo realizados com o objetivo de substituir esses materiais por outros óxidos, tais como óxido de manganês e vanádio, o que envolve estudos relacionados a mudanças estruturais durante os ciclos de carga e descarga, influência da estrutura cristalina na capacidade de carga, entre outros. ${ }^{81}$ Além disso, o desempenho dos materiais para cátodo pode ser melhorado aumentando-se a sua área superficial, uma vez que o processo é limitado pela difusão de íons em sua estrutura; ${ }^{82}$ por isso, a obtenção e caracterização de eletrodos nanoestruturados vem sendo de grande importância para o desenvolvimento de dispositivos de alta energia. ${ }^{83}$

Desde que Poizot et al.$^{84}$ reportaram a potencialidade de utilização de metais de transição nanoestruturados $(\mathrm{MxOy}$, onde $\mathrm{M}=\mathrm{Ni}, \mathrm{Fe}$, $\mathrm{Co} \mathrm{ou} \mathrm{Cu}$ ) como materiais ativos para baterias de íon lítio, esta área vem crescendo exponencialmente nos últimos anos, procurando-se um material de maior capacidade eletroquímica do que o material padrão comercial, a grafite $\left(372 \mathrm{~mA} \mathrm{~h} \mathrm{~g}^{-1} .{ }^{85} \mathrm{~A}\right.$ reação entre o óxido de níquel com o lítio não é uma simples intercalação, mas um processo de conversão, segundo a Equação 4:

$$
\mathrm{NiO}+2 \mathrm{Li}^{+} \leftrightarrows \mathrm{Li}_{2} \mathrm{O}+\mathrm{Ni}+2 \mathrm{e}
$$

Esta reação leva à formação de níquel metálico e nanoestruturas de $\mathrm{LiO}_{2}$, juntamente com uma expansão de volume bastante pronunciada. Quando o $\mathrm{NiO}$ é usado como material anódico para baterias de íon lítio sua capacidade teórica é cerca de $718 \mathrm{~mA} \mathrm{~h} \mathrm{~g}^{-1}$, entretanto o processo de expansão/contração pode levar à degradação dos eletrodos, ocasionando uma capacidade de ciclagem reduzida. Uma alternativa para amenizar este problema está na síntese de partículas de tamanho reduzido. Recentemente foi reportada a utilização de nanowalls de $\mathrm{NiO}$, produzindo um excelente comportamento durante a ciclagem contínua. ${ }^{86}$ Além deste, a síntese de nanodiscos de $\beta-\mathrm{Ni}(\mathrm{OH})_{2}$, produziu um eletrodo com uma alta ciclagem, embora com baixa capacidade de carga. ${ }^{87}$ Liu et al ${ }^{88}$ descreveram a síntese solvotérmica de microesferas de $\mathrm{NiO}$ seguida por calcinação, na qual uma capacidade de carga inicial de $1570 \mathrm{~mA} \mathrm{~h} \mathrm{~g}^{-1}$ foi obtida, além de uma alta inserção de íons lítio pela estrutura micrométrica. Embora os resultados iniciais sejam muito promissores, ainda foi encontrada uma baixa durabilidade do eletrodo, como pode ser observado na Figura 9, que mostra as curvas de carga/descarga deste eletrodo durante diversos ciclos.

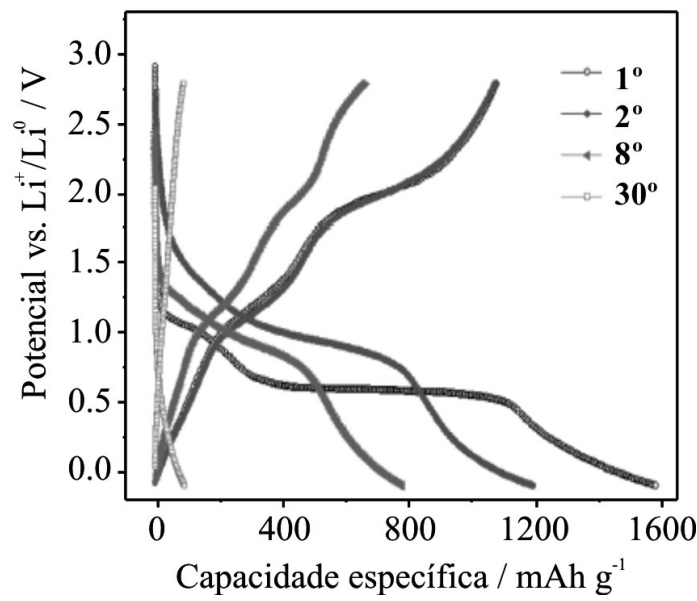

Figura 9. Curvas de carga/descarga obtidas para eletrodos modificados por microesferas de $\mathrm{NiO}$ testadas em densidade de corrente de $50 \mathrm{mAg}^{-1}$, na faixa de potencial de 0,01-3,0 V. Reproduzido da ref. 88, com autorização da ACS

\section{CONCLUSÕES}

Este trabalho descreveu as principais características estruturais e eletroquímicas do hidróxido de níquel e sua aplicação em dispositivos eletrocrômicos, sistemas eletrocatalíticos e baterias secundárias. Devido à sua grande versatilidade, o mesmo sempre esteve em destaque dentro da comunidade científica e, assim como com outros materiais, sua pesquisa sofreu um novo e promissor estímulo com a incorporação da nanotecnologia. Atualmente podem ser encontrados diversos trabalhos dedicados somente à sua síntese na escala nanométrica, porém é importante salientar que mesmo os materiais clássicos, ou seja, em dimensões não nanométricas ainda são bastante empregados em diversas áreas.

\section{LISTA DE ABREVIAÇÕES}

XDR - Difração de Raios X

IV - Espectroscopia no Infravermelho

MECQ - Microbalança Eletroquímica a Cristal de Quartzo

FTIR - Espectroscopia no infravermelho empregando transformada de Fourrier

EDAX - Espectroscopia de Energia Dispersiva

SEM - Microscopia Eletrônica de Varredura

TEM - Microscopia Eletrônica de Transmissão

HRTEM - Microscopia Eletrônica de Transmissão de Alta Resolução

TGA - Termogravimetria

BET - Teoria de adsorção de Brunnauer-Emmet-Teller

ICP-OES - Espectroscopia de emissão atômica acoplada com plasma AFM - Microscopia de Força Atômica

$\Delta \% \mathrm{~T}$ - variação de transmitância

$\Delta \% \mathrm{~A}$ - variação de absorbância

$\eta$ - eficiência eletrocrômica

Q - carga elétrica

$\tau$ - tempo de resposta eletrocrômico

ITO - óxido de estanho dopado com índio

FTO - óxido de estanho dopado com flúor

FIA - Análise por Injeção de Fluxo

LbL - deposição por camadas eletrostáticas

EPD - deposição eletroforética

VC - voltametria cíclica

AAS - absorção atômica

\section{REFERÊNCIAS}

1. Casey, E. J.; Dubois, A. R.; Lake, P. E.; Moroz, W. J.; J. Electrochem. Soc. 1965, 112, 371; Kober, F. P.; J. Electrochem. Soc. 1967, 114, 215; Macarthu, D. M.; J. Electrochem. Soc. 1968, 115, C79; Appelt, K.; Electrochim. Acta 1968, 13, 1727; Macarthu, D. M.; J. Electrochem. Soc. 1970, 117, 729.

2. Kruijt, W. S.; Bergveld, H. J.; Notten, P. H. L.; J. Electrochem. Soc. 1998, 145, 3764; Viitanen, M.; J. Electrochem. Soc. 1993, 140, 936; Notten, P. H. L.; NATO ASI Ser, Ser. E 1995, 281, 151; Notten, P. H. L.; van Beek, J. R. G.; Chem. Ind. 2000, 54, 102; Varela, H.; Huguenin, F.; Malta, M.; Torresi, R. M.; Quim. Nova 2002, 25, 287; Ambrosio, R. C.; Ticianelli, E. A.; Quim. Nova 2001, 24, 243; Thaller, L. H.; Zimmerman, A. H.; J. Power Sources 1996, 63, 53; Geng, M.; Northwood, D. O.; Int. J. Hydrogen Energy 2003, 28, 633.

3. Hoare, J. P., ed.; The Electrochemistry of Oxygen, John Wiley \& Sons, Inc.: New York, 1968, p. 271; Corrigan, D. A.; Bendert, R. M.; J. Electrochem. Soc. 1989, 136, 723.

4. Cox, P.; Pletcher, D. J.; J. Appl. Electrochem. 1990, 20, 549; Schäfer, H. J.; Scheider, R.; Tetrahedron 1991, 46, 715; Fleischmann, M.; Korinek, K.; Pletcher, D. J.; J. Electroanal. Chem. 1971, 31, 39; Kaulen, J.; Schafer, H. J.; Tetrahedron 1982, 38, 3299; Grill, J. M.; Ogle, J. W.; Miller, S. A.; J. Org. Chem. 2006, 71, 9291. 
5. Alivisatos, A. P.; J. Phys. Chem. 1995, 100, 13226; Trindade, T.; O'Brien, P.; Pickett, N. L.; Chem. Mater. 2001, 13, 3843; Wang, Y.; Herron, N.; J. Phys. Chem. 1991, 95, 525.

6. Hseih, C. T.; Huang, W. L.; Lue, J. T.; J. Phys. Chem. Sol. 2002, 63, 733.

7. Ajayan, P. M.; Chem Rev. 1999, 99, 1787; Thostenson, E. T.; Ren, Z.; Chou, T. W.; Compos. Sci. Technol. 2001, 61, 1899; Dumitrescu, I.; Unwin, P. R.; Macpherson, J. V.; Chem. Commun. 2009, 6886.

8. Haruta, M.; Catal. Today 1997, 36, 153; Sakurai, H.; Haruta, M.; Catal. Today 1996, 29, 361; Daniel, M. C.; Astruc, D.; Chem Rev. 2004, 104 293.

9. Mulvaney, P.; Langmuir 1996, 12, 788; Alvarez, M. M.; Khoury, J. T.; Schaaff, T. G.; Shafigullin, M. N.; Vezmar, I.; Whetten, R. L.; J. Phys. Chem. B 1997, 101, 3706; Damos, F. S.; Luz, R. C. S.; Kubota, L. T. Langmuir 2005, 21, 602.

10. Audemer, A.; Delahaye, A.; Farhi, R.; Eppe, N. S.; Tarascon, J. M.; J. Elecrochem. Soc. 1997, 144, 2614; Vidal, A. D.; Figlarz, M.; J. Appl. Electrochem. 1987, 17, 589; Acharya, R.; Subbaiah, T.; Anand, S.; Das, R. P.; J. Power Sources 2002, 109, 494.

11. Bode, H.; Dehmelt, K.; Witte, J.; Electrochim. Acta 1966, 11, 1079.

12. Faure, C.; Delmas, C.; Fouassier, M.; J. Power Sources 1991, 35, 279.

13. Faure, C.; Delmas, C.; Willmann, P.; J. Power Sources 1991, 35, 263.

14. Guerlou, L. D.; Delmas, C.; J. Power Sources 1993, 45, 281; Oliva, P.; Leonard, J.; Laurert, J. F.; Delmas, C.; Braconnier, J. J.; Figlarz, M.; Fievet, F.; Guibert, A.; J. Power Sources 1982, 8, 229; Nakamoto, K.; Infrared and Raman Spectra of Inorganic and Coordination Compounds, Wiley: New York, 1986.

15 Mani, B.; Neufville, J. P.; J. Electrochem. Soc. 1988, 135, 800; Freitas, M. B. J. G.; J. Power Sources 2001, 93, 163; Le Bihan, S.; Figlarz, M.; Thermochim. Acta 1973, 6, 319.

16. Bernard, M. C.; Bernard, P.; Keddam, M.; Seyarich, S.; Takenouti, H.; Electrochim. Acta 1996, 41, 91; Deabate, S.; Fourgeot, F.; Henn, F.; J. Power Sources 2000, 87, 125; Desilvestro, J.; Corrigan, D. A.; Weaver, M. J.; J. Electrochem. Soc. 1998, 135, 885.

17 Bernard, M. C.; Cortes, R.; Keddam, M.; Takenouti, H.; Bernard, P.; Seyarich, S.; J. Power Sources 1996, 63, 247; Vidotti, M.; Salvador, R. P.; Ponzio, E. A.; Córdoba de Torresi, S. I.; J. Nanosci. Nanotechnol. 2007, 7, 3221 .

18. Hu, Y.; Bae, I. T.; Mo, Y.; Antonio, M. R.; Scherson, D. A.; Can. J. Chem. 1997, 75, 1721; Nam, K. W.; Yoon, W. S.; Kim, K. B.; Electrochim. Acta 2002, 47, 3201; Chen, R. R.; Mo, Y.; Scherson, D. A.; Langmuir 1994, 10, 3933; Dijksma, M. W.; Notten, P. H. L.; Electrochim. Acta 2006, 51, 3609; Roto. R.; Yamagishi, A.; Villemure, G.; J. Electroanal. Chem. 2004, 572, 101; Grden, M.; Klimek, K.; J. Electroanal. Chem. 2005, 581, 122.

19. Kim, M. S.; Kim, K. B.; J. Electrochem. Soc. 1998, 145, 507.

20. Kamath, P. V.; Dixit, M.; Indira, L.; Shukla, A. K.; Kumar, V. G.; Munichandraiah, N.; J. Electrochem. Soc. 1994, 141, 2956; Hu, M.; Gao, X.; Lei, L.; Sun, Y.; J. Phys. Chem. C 2009, 113, 7448.

21. Ismail, J.; Ahmed, M. F.; Kamath, P. V.; J. Power Sources 1991, 36, 507; Douin, M.; Demourgues, L. G.; Goubault, L.; Bernard, P.; Delmas, C.; J. Electrochem. Soc. 2009, 156, A459.

22. Córdoba de Torresi, S. I.; Carbonio, R. E.; Teijelo, M. L.; Macagno, V. A.; Electrochim. Acta 1988, 31, 132.

23. Guerlou, L. D.; Delmas, C.; J. Power Sources 1993, 45, 281; Kim, S.; Tryk, D. A.; Antonio, M. R.; Cam, R.; Scherson, D.; J. Phys. Chem. 1994, 98, 10269.

24. Corrigan, D. A.; Bendert, R. M.; J. Electrochem. Soc. 1989, 136, 723.

25. Provazi, K.; Giz, M. J.; Dall'Antonia, L. H.; Córdoba de Torresi, S. I.; J. Power Sources 2001, 102, 224; Kruijt, W. S.; Bergveld, H. J.; Notten, P. H. L.; J. Electrochem. Soc. 1998, 145, 3764.

26. Falk, S. U.; Salkind, A. J.; Alkaline Storage Batteries, John Wiley \& Sons: New York, 1969.

27. Zhao, Y. L.; Wang, J. M.; Chen, H.; Pan, T.; Zhang, J. Q.; Cao, C. N.; Int. J. Hydrogen. Energy 2004, 29, 889.
28. Faure, C.; Delmas, C.; Willmann, P.; J. Power Sources 1991, 36, 497.

29. Córdoba de Torresi, S. I.; Electrochim. Acta 1995, 40, 1101.

30. Saiah, F. B.; Su, B. L.; Bettahar, N.; J. Hazard. Mater. 2009, 165, 206.

31. Vidotti, M.; Chague, C.; Córdoba de Torresi, S. I.; Semina 2007, 28, 173.

32. Provazi, K.; Giz, M. J.; Dall'Antonia, L. H.; Córdoba de Torresi, S. I.; J. Power Sources 2001, 102, 224.

33. Córdoba de Torresi, S. I.; Provazi, K.; Malta, M.; Torresi, R. M.; J. Electrochem. Soc. 2001, 148, A1179.

34. Pejova, B.; Kocareva, T.; Najdoski, M.; Grozdanov, I.; Appl. Surf. Sci. 2000, 165, 271; Wang, Y.; Zhu, Q. S.; Zhang, H. G.; Chem. Commun. 2005, 41, 523; Liu, L.; Li, Y.; Yuan, S. M.; Ge, M.; Ren, M. M.; Sun, C. S.; Zhou, Z.; J. Phys. Chem. C. 2010, 114, 251; Coudun, C.; Amblard, E.; Guihaume, J.; Hochepied, J. F.; Catal. Today 2007, 124, 49.

35. Akinca, M.; Jongenb, N.; Lemaitreb, J.; Hofmannb. H.; J. Eur. Cer. Soc. 1998, 18, I559; Zhao, Y. L.; Wang, J. M.; Chen, H.; Pan, T.; Zhang, J. Q.; Cao, C. N.; Electrochim. Acta 2004, 50, 91; Merlin, A.; Teichner, S.; J. Acad. Sci. 1953, 236, 1892.

36. Santana, A. I. C.; Díaz, S. L.; Barcia, O. E.; Mattos, O. R.; J. Electrochem. Soc. 2009, 156, D326; Wiart, R.; Electrochim. Acta 1990, 35, 1587; Epelboin, I.; Jousselin, M.; Wiart, R.; J. Electroanal. Chem. 1981, 119, 61; Chassaing, E.; Jousselin, M.; Wiart, R.; J. Electroanal. Chem. 1983, 157,75 .

37. Desilvestro, J.; Corrigan, D. A.; Weaver, M. J.; J. Electrochem. Soc. 1988, 135, 885; Bendert, R. M.; Corrigan, D. A.; J. Electrochem. Soc. 1989, 136, 1369.

38. Wu, M. S.; Huang, Y. A.; Yang, C. H.; J. Electrochem. Soc. 2008, 155, A798; Wu, M. S.; Huanga, Y. A.; Jowa, J. J.; Yanga, W. D.; Hsieh, C. Y.; Tsai, H. M.; Int. J. Hydrogen Energy 2008, 33, 2921.

39. Nam, K. W.; Kim, K. B.; J. Electrochem. Soc. 2002, 149, A346.

40. Chang, Y.; Qiao, J.; Liu, O.; Shangguan, L.; Ma, X.; Shuang, S.; Dong, C.; Anal. Lett. 2008, 41, 3147; Deo, R. P.; Lawrence, N. S.; Wang, J.; Analyst 2004, 129, 1076.

41. Hiller, R.; Putterman, S. J.; Barber, B. P.; Phys. Rev. Lett. 1992, 69, 1182; Barber, B. P.; Putterman, S. J.; Nature 1991, 352, 414; Suslick, K. S.; Hammerton, D. A.; Cline Jr., R. E.; J. Am. Chem. Soc. 1986, 108, 5641; Gedanken, A.; Ultras. Sonochem. 2004, 11, 47.

42. Suslick, K. S.; Choe, S. B.; Cichowlas, A. A.; Grinstaff, M. W.; Nature 1991, 353, 414.

43. Jeevanandam, P.; Koltypin, Y.; Gedanken, A.; Nano Lett. 2001, 1, 263.

44. Vidotti, M.; Salvador, R. P.; Córdoba de Torresi, S. I.; Ultrason. Sonochem. 2009, 16, 35.

45. de Oliveira, S. C.; Torresi, R. M.; Córdoba de Torresi, S. I.; Quim. Nova 2000, 23, 79; Granqvist, C. G.; Handbook of Inorganic Electrochromic Materials, Elsevier: Amsterdan, 1995; Rosseinsky, D. R.; Mortimer, R. J.; Adv. Mater. 2001, 13, 783.

46. Vidotti, M.; Córdoba de Torresi, S. I.; J. Braz. Chem. Soc. 2009, 19, 1248; Bonhôte, P.; Goniat, E.; Campus, F. ; Walder, L.; Grätzel, M.; Displays 1999, 20, 137; Cummins, D.; Boscholoo, G.; Ryan, C, D.; Rao, N.; Fiyzmaurice, F.; J. Phys. Chem. B 2000, 104, 11449; Baioni, A. P. ; Vidotti, M. ; Fiorito, P. A. ; Ponzio, E. A. ; Córdoba de Torresi, S. I.; Langmuir 2007, 23, 6796.

47. Detcher, G.; Science 1997, 277, 1232; Kim, H. S.; Sohn, B. H.; Lee, W.; Lee, J. K.; Choi, S. J.; Kwon, S. J.; Thin Solid Films 2002, 419, 173; Ostrander, J. W.; Mamedov, A. A.; Kotov, N. A.; J. Am. Chem. Soc. 2001, 123, 1101; Shinbo, K.; Onishi, K.; Miyabayashi, S.; Takahashi, K.; Katagiri, S.; Kato, K.; Kaneko, F.; Advincula, R. C.; Thin Solid Films 2003, 439, 177; Lvov, Y.; Ariga, K.; Onda, M.; Ichinose, I.; Kunitake, T.; Langmuir 1997, 13, 6195; Huguenin, F.; Gonzales, E. R.; Oliveira Jr, O. N.; J. Phys. Chem. B 2005, 109, 12837; Cutler, C. A.; Bouguettaya, M.; Reynolds, J. R.; Adv. Mater. 2002, 14, 684; DeLongchamp, D. M.; Kastantin, M.; Hammond, P. T.; Chem. Mater. 2003, 15, 1575.

48. Gani, M. S. J.; Ind. Ceram. 1994, 14, 163; Sarkar, P.; Nicholson, P. S.; J. Am. Ceram. Soc. 1996, 79, 1987. 
49. Gao, B.; Yue, G. Z.; Qiu, Q.; Cheng, Y.; Shimoda, H.; Fleming, L.; Zhou, O.; Adv. Mater. 2001, 13, 1770; Affoune, A. M.; Prassad, B. L. V.; Sato, H.; Enoki, T.; Langmuir 2001, 17, 547; Limmer, S. J.; Seragi, S.; Wu, Y.; Chou, T. P.; Nguyen, C.; Cao, G.; Adv. Funct. Mater. 2002, 12, 59; Teranishi, T.; Hosoe, M.; Tanaka, T.; Miyake, M.; J. Phys. Chem. B 1999, 103, 3818; Vidotti, M.; Gonçales, V. R.; Quartero, V. R.; Danc, B.; Córdoba de Torresi, S. I.; J. Solid State Electrochem. 2010, 14, 675.

50. Vidotti, M.; Córdoba de Torresi, S. I.; Eletrochim. Acta 2009, 54, 2800.

51. Chigane, M.; Ishikawa, M.; Eletrochim. Acta 1997, 42, 1515.

52. Koroseca, R. C.; Bukoveca, P.; Pihlara, B.; Vukb, A. S.; Orel, B.; Drazic, G.; Solid State Ionics 2003, 165, 191.

53. Surca, A.; Orel, B.; Pihlar, B.; J. Solid State Electrochem. 1998, 2, 38.

54. Vidotti, M.; Greco, C. V.; Ponzio, E. A.; Córdoba de Torresi, S. I.; Electrochem. Commun. 2006, 8, 554.

55. Sonavane, A. C.; Inamdar, A. I.; Shinde, P. S.; Deshmukh, H. P.; Patil, R. S.; Patil, P. S.; J. Alloys Comp. 2010, 489, 667.

56. Surca, A.; Orel, B.; Pihlar, B.; J. Sol Gel Sci. Technol. 1997, 8, 743.

57. Wang, J.; Electroanal. 2001, 13, 983; Wang, C.; Ma, Z.; Wang, T.; Su, Z.; Adv. Funct. Mater. 2006, 16, 1673; Zhang, Y.; Wang, H.; Yan, B.; Zhang, Y.; Li, J.; Shen, G.; Yu, R. J.; Immunol Methods 2008, 332, 103; Storhoff, J. J.; Lazarides, A. A.; Mucic, R. C.; Mirkin, C. A.; Letsinger, R. L.; Schatz, G. C.; J. Am. Chem. Soc. 2000, 122, 4640; Li, X.; Shen, L.; Zhang, D.; Qi, H.; Gao, Q.; Ma, F.; Zhang, C.; Biosens. Bioelectron. 2008, 23, 1624; Baioni, A. P.; Vidotti, M.; Fiorito, P. A.; Córdoba de Torresi, S. I.; J. Electroanal. Chem. 2008, 622, 219; Yang, W.; Li, Y.; Bai, Y.; Sun, C. ; Sens. Actuators B 2006, 115, 42.

58. Lähdesmäki, I.; Lewenstam, A.; Ivaska, A.; Talanta 1996, 43, 125; Vidotti, M.; Dall'Antonia, L. H.; Bergamaski, K.; Córdoba de Torresi, S. I.; Nart, F. C. ; Anal. Chim. Acta 2003, 489, 207; Mohammadi, A.; Inganas, O.; Lundström, I. ; J. Electrochem. Soc. 1986, 133, 947; Diaz, A. F.; Castillo, J. J.; Logan, J. A.; Lee, W.; J. Electroanal. Chem. 1981, 129, 115; Dall'Antonia, L. H.; Vidotti, M.; Torresi, R. M.; Córdoba de Torresi, S. I.; Electroanalysis 2002, 14, 157; Vidotti, M.; Dall'Antonia, L. H.; Cintra, E. P.; Córdoba de Torresi, S. I.; Electrochim. Acta 2004, 49, 3665 .

59. Quintino, M. S. M.; Araki, K.; Toma, H. E.; Angnes L.; Electroanalysis 2002, 14, 1629; Quintino, M. S. M.; Araki, K.; Toma, H. E.; Angnes, L.; Talanta 2006, 68, 1281; Thomas, P. C.; Halter, M.; Tona, A.; Raghavan, S. R.; Plant, A. L.; Forry, S. P.; Anal. Chem. 2009, 81, 9239; Santos, W. D. R.; Sousa, A. L.; Sotomayor, M. D. T.; Damos, F. S.; Tanaka, S. M. C. N.; Kubota, L. T.; Tanaka, A. A.; J. Braz. Chem. Soc. 2009, 20, 1180; Santos, W. J. R.; Sousa, A. L.; Luz, R. C. S.; Damos, F. S.; Kubota, L. T.; Tanaka, A. A.; Tanaka, S. M. C. N.; Talanta 2006, 70, 588.

60. Zhang, C.; Debliquy, M.; Boudiba, A.; Liao, H. L.; Coddet, C.; Sens. Actuators, B 2010, 144, 280; Zakrzewska, K.; Thin Solid Films 2001, 391, 229; Li, S. F.; Li, F. P.; Rao, Z. M.; Sens. Actuators, B 2010, 145, 78; Zhu, Y. F.; Shi, J. J.; Zhang, Z. Y.; Zhang, C.; Zhang, X. R.; Anal. Chem. 2002, 74, 120; Comini, E.; Anal. Chim. Acta 2006, 568, 28.

61. You, T.; Niwa, O.; Chen, Z.; Hayashi, K.; Tomita, M.; Hirono, S.; Anal. Chem. 2003, 75, 5191.

62. Vidotti, M.; Silva, M. R.; Salvador, R. P.; Córdoba de Torresi, S. I.; Dall'Antonia, L. H.; Electrochim. Acta 2008, 53, 4030.

63. Vidotti, M.; Córdoba de Torresi, S. I. C.; Kubota, L. T.; Sens. Actuators, B 2008, 135, 245; Zheng, L.; Song, J. F.; Anal. Biochem. 2009, 391, 56.

64. Giovanelli, D.; Lawrence, N. S.; Jiang, L.; Jones, T. G. J.; Compton, R. G.; Sens. Actuators, B 2003, 88, 320.

65. Casella, I. G.; Cataldi, T. R. I.; Desimoni, E.; Anal. Chem. 1993, 65, 3143; Stradiotto, N. R.; Toghill, K. E.; Xiao, L.; Moshar, A.; Compton, R. G.; Electroanalysis 2009, 21, 2627.

66. Hajjizadeh, M.; Jabbari, A.; Heli, H.; Movahedi, A. A. M.; Haghgoo, S.; Electrochim. Acta 2007, 53, 1766.

67. Safavi, A.; Malekia, N.; Farjami E.; Biosens. Bioelectron. 2009, 24, 1655.
68. You, T. Y.; Niwa, O.; Chen, Z. L.; Hayashi, K.; Tomita, M.; Hirono, S.; Anal Chem. 2003, 75, 5191.

69. Casella, I. G.; Guascito, M. R.; Cataldi, T. R. I.; Anal. Chim. Acta 1999 $398,153$.

70. Vidotti, M.; Cerri, C. C.; Carvalhal, R. F.; Dias, J. C.; Mendes, R. K.; Córdoba de Torresi, S. I.; Kubota, L. T.; J. Electroanal. Chem. 2009, 636, 18.

71. Yi, Q.; Huang, W.; Yu, W.; Li, L.; Liu, X.; Electroanal. 2008, 20, 2016.

72. Li, Y.; Song, Y. Y.; Yang, C.; Xia, X. H.; Electrochem. Commun. 2007, 9, 981.

73. Ye, J. S.; Wen, Y.; Zhang, W. D.; Gan, L. M.; Xu, G. Q.; Sheu, F. S.; Electrochem. Commun. 2004, 6, 66.

74. Yu, J.; Liu, S.; Ju, H.; Biosens. Bioelectron. 2003, 19, 401

75. Cosnier, S.; Senillou, A.; Grätzel, M.; Comte, P.; Vlachopoulos, N.; Renault, N. J.; Martelet, C.; J. Electroanal. Chem. 1990, 469, 176.

76. Wasmus, S.; Kuver, A.; J. Electroanal. Chem. 1999, 461, 14; Carrete, L.; Friedrich, K. A.; Stimming, U.; Chem. Phys. Chem. 2000, 1, 164; Viglier, F.; Coutanceau, C.; Perrard, A.; Belgsir, E. M.; Lamy, C.; J. Appl. Electrochem. 2004, 34, 439.

77. Wang, Z. L.; Liu, Y.; Linkov, V. M.; J. Power Sources 2006, 160, 326; Girishkumar, G.; Vinodgopal, K.; Kamat, P. V.; J. Phys. Chem. B 2004, 108, 19960; Villullas, H. M.; Mattos-Costa, F. I.; Bulhoes, L. O. S.; J. Phys. Chem. B 2004, 108, 12898; Huang, S. Y.; Chang, C. M.; Wang, K. W.; Yeh, C. T.; ChemPhysChem 2007, 8, 1774.

78. Parsons, R.; Vander Noot, T.; J. Electroanal. Chem. 1988, 257, 9; Nishimura, K.; Machida, K.; Enyo, M.; J. Electroanal. Chem. 1988, 251, 117.

79. Yi, Q.; Huang, W.; Zhang, J.; Liu, X.; Li, L.; Catal. Commun. 2008, 9, 2053; El-Shafei, A. A.; J. Electroanal. Chem. 1999, 471, 89; Weng, Y. C.; Chou, T. C.; J. Electrochem. Soc. 2006, 153, H127; Danaeea, I.; Jafariana, M.; Forouzandeha, F.; Gobalb, F.; Mahjania, M. G.; Int. J. Hydrogen Energy 2008, 33, 4367; Cox, P.; Pletcher, D.; J. Appl. Electrochem. 1990, 20, 549.

80. Brodd, R. J.; Tagawa, K.; Advances in Lithium-ion batteries, Plenum Publishing corp.: New York, 2002, cap. 9.

81. Varela, H.; Huguenin, F.; Malta, M.; Torresi, R. M.; Quim. Nova 2007, 25, 287; Ammundsen, B.; Paulsen, J.; Adv. Mater. 2001, 13, 12; Xu, J. J.; Ye, H.; Jain, G.; Yang, J.; Electrochem. Commun. 2004, 6, 892; Rocquefelte, X.; Boucher, F.; Grassier, P.; Ouvrard, G. ; Chem. Mater. 2003, 15, 1812

82. Miller, R. J.; Simon, P.; The Electrochem. Soc. Interface 2008, 17, 31.

83. Wang, Y.; Cão, G.; Adv. Mater. 2008, 20, 2251; Wronski, Z. S.; Varin, R. A.; Czujko, T.; J. Nanosci. Nanotechnol. 2009, 9, 4048.

84. Poizot, P.; Laruelle, S.; Grugeon, S.; Dupont, L.; Tarascon, J. M.; Nature 2000, 407, 496.

85. Huang, X. H.; Tu, J. P.; Zhang, C. Q.; Xiang, J. Y.; Electrochem. Commun. 2007, 9, 1180; Reddy, M. V.; Yu, T.; Sow, C.-H.; Shen, Z. X.; Lim, C. T.; Subba Rao, G. V.; Chowdari, B. V. R.; Adv. Funct. Mater. 2007, 17, 2792; Li, W.-Y.; Xu, L.-N.; Chen, J.; Adv. Funct. Mater. 2005, 15, 851; Gao, X. P.; Bao, J. L.; Pan, G. L.; Zhu, H. Y.; Huang, P. X.; Wu, F.; Song, D. Y.; J. Phys. Chem. B 2004, 108, 5547; Yuan, L.; Guo, Z. P.; Konstantinov, K.; Munroe, P.; Liu, H. K.; Electrochem. Solid-State Lett. 2006, 9, A524.

86. Varghese, B.; Reddy, M. V.; Zhu, Y. W.; Chang, S. L.; Hoong, T. C.; Subba Rao, G. V.; Chowdari, B. V. R.; Wee, A. T. S.; Lim, C. T.; Sow, C. H.; Chem. Mater. 2008, 20, 3360; Wang, X.; Li, L.; Zhang, Y. G.; Wang, S. T.; Zhang, Z. D.; Fei, L. F.; Qian, Y. T.; Cryst. Growth Des. 2006, 6, 2163; Liu, L.; Liu, H. J.; Kou, H. Z.; Wang, Y. Q.; Ren, M. M.; Zhou, Z.; Ge, M.; He, X. W.; Cryst. Growth Des. 2009, 9, 113.

87. Sakai, G.; Miyazaki, M.; Kijima, T.; J. Electrochem. Soc. 2010, 157, A480.

88. Liu, L.; Li, Y.; Yuan, S.; Ge, M.; Ren, M.; Sun, C.; Zhou, Z.; J. Phys. Chem. C 2010, 114, 251 